Article

\title{
Digital Control of an Interleaving Operated Buck-Boost Synchronous Converter Used in a Low-Cost Testing System for an Automotive Powertrain
}

\author{
Miran Rodič *(D), Miro Milanovič (D) and Mitja Truntič \\ Faculty of Electrical Engineering and Computer Science, University of Maribor, Koroška cesta 46, \\ SI-2000 Maribor, Slovenia; miro.milanovic@um.si (M.M.); mitja.truntic@um.si (M.T.) \\ * Correspondence: miran.rodic@um.si; Tel.: +386-2-220-7308
}

Received: 9 August 2018; Accepted: 27 August 2018; Published: 30 August 2018

\begin{abstract}
Based on the standardization in the automotive industry, systems require extensive testing, which represents significant costs regarding personnel and equipment. The testing systems must be built in such a way that a bidirectional power flow is possible between the power source and the tested system. Additionally, applied testing systems have to possess high disturbance immunity. Classical current programmed control performed using an analogue approach suffers from low disturbance rejection during switching operation. The digital control of DC-DC converter can solve this problem with the use of digital integration in a measurement chain. The integrals of values are obtained by using a Voltage Control Oscillator (VCO) and appropriate counters. Digital control of an interleaving operated bidirectional buck-boost synchronous converter can be applied in the testing system for automotive powertrains. The voltage and current measurements with the application of an integral-measurement principle act as low-pass filters, which remove the disturbances from the measured values. The digital implementation of a compensation ramp (current mode control) and method for choice of control parameters are described. All the tasks for measurements, as well as current and voltage control, were implemented within the FPGA (Field Programmable Gate Array). The presented converter can operate as a close to ideal voltage or current source, and satisfies the requirements of testing electric motor drive-trains with bidirectional DC-AC converters that are applied in automotive applications. The proposed system was verified by simulation and experiments.
\end{abstract}

Keywords: power electronics converter; voltage and current control; measured integrals by using VCOs

\section{Introduction}

In the development of safety-critical applications, testing is an essential part of the development process [1]. Industry standards and guidelines emerged, since functional safety of such devices has to be proven. The main standard covering this area is IEC/ISO 61508 [2]. It is intended to be a basic standard and is applicable to all industry fields. Additional standards were developed regarding the functional safety in specific industries, for example IEC/ISO 26262 for road vehicles [3]. Companies active in the automotive industry are, thus, often, faced with the testing of their products according to industry standards, which can become quite costly from the viewpoint of work intensity and costs of equipment. This is especially true for the Small and Medium Enterprises (SMEs).

Testing of powertrains and auxiliary drives in automotive applications is of special interest. The drive under test is connected to the dynamometer mechanically, which can be torque or speed 
controlled, emulating the actual load torque that would be present on the motor shaft in the actual application [4-6]. Some possible setups of the testing system are presented in Figure 1. DM represents a "drive machine", the motor of the powertrain under test, whereas LM is the "load machine", the dynamometer applied to emulate the loading of the tested powertrain when operating. Both drive and dynamometer, are driven by DC-AC converters. The DC-AC inverter of the drive powertrain can be uni- or bidirectional, whereas the dynamometer DC-AC inverter has to be bidirectional. Different kinds of DC-AC converters can be expected to be used in the automotive powertrains. Most applications use the Voltage Source Inverter [7,8], but also multilevel inverters $[9,10]$ and Current Source Inverters [9] are becoming an option. Voltage Source Inverters are the most commonly used inverters. Multilevel Inverters have the advantage of enabling an improved Pulse Width Modulation (PWM) quality and a simple voltage sharing [7], harmonic mitigation is also of interest [11,12]. Their disadvantages are the neutral-point voltage balancing that can become difficult and complex control circuits. Current Source Inverters require a current source. For all types of DC-AC converters, the analysis has to be performed regarding harmonic distortion and related issues [13-17].

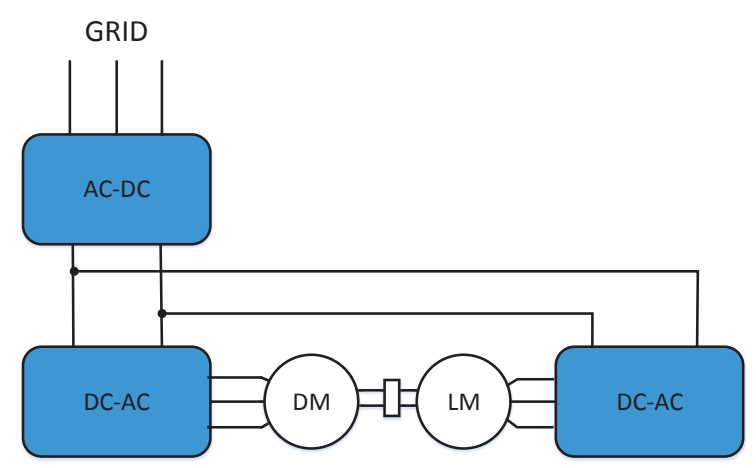

(a)

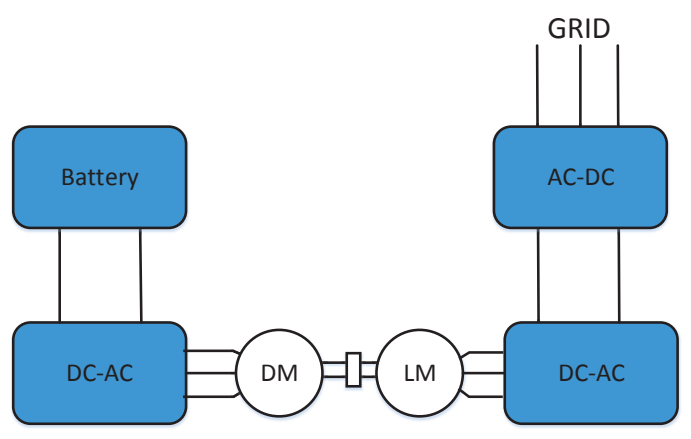

(c)

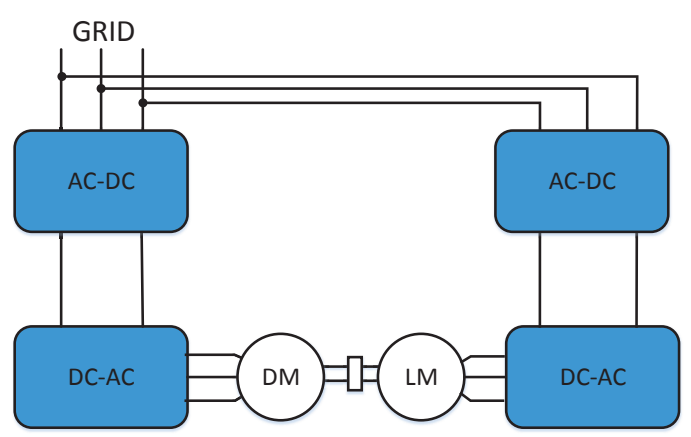

(b)

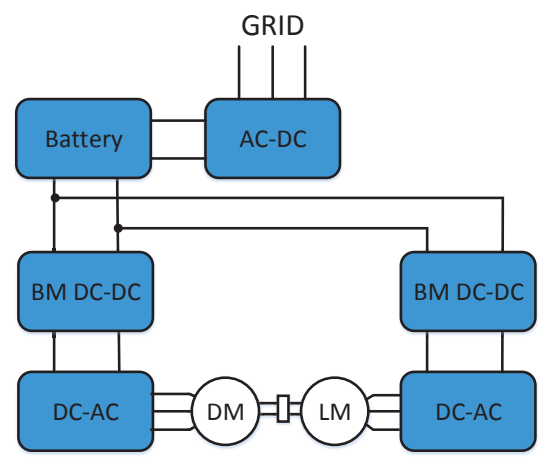

(d)

Figure 1. Simplified electrical schemes of electric powertrain testing system: (a) common DC-link; (b) separate AC-DC converters for drive and dynamometer; (c) battery-driven drive and grid connected dynamometer; (d) battery and two bidirectional multiphase DC-DC converters.

Well-known testing systems setups are shown in Figure 1 [4-6]. The setup in Figure 1a features a common DC-link system for vehicle powertrain testing. In such systems, the DC-links of the powertrain and dynamometer are connected, thus enabling four-quadrant operation of the tested powertrain. Only one grid-connected AC-DC converter is used, thus the voltages of the DC-link 
are the same, which is not practical, since, for the different applications, different voltages are also required, and a dedicated dynamometer converter would be needed for every voltage range.

The setup in Figure 1b would be more appropriate in such cases, using separate bidirectional AC-DC converters for drive and dynamometer. Some functional safety tests require testing of short-cut and open-circuit operation, which can have an undesired effect on the grid. In addition, the price of the high-power connection to the grid is sometimes unacceptable for SMEs. This is also the case for the setup in Figure 1c, where the battery is used to charge the drive under test. During the operation, the battery is discharged and the dynamometer operates as a generator, sending the generated energy directly to the power grid.

In order to avoid all of these "obstacles", the system shown in Figure 1d is suggested, which is somewhat more suitable for testing in SMEs than the previous ones. The interleaving operated multiphase buck and boost converters can be used in the laboratory environments for testing purposes [18-20]. The grid connection can be "normal" power rated (up to $5 \mathrm{~kW}$ ), which is an important benefit regarding the grid connection expenses for SMEs. The voltages of the DC-links can be adjusted separately for both the tested drivetrain and dynamometer using bidirectional DC-DC converters. Energy is cycled between the tested powertrain and dynamometer through bidirectional DC-DC converters with the battery only covering losses. Thus, the battery can be used even for long-term testing, only requiring charging relatively rarely, possibly overnight. The bidirectional multiphase DC-DC (BM DC-DC) converters, as used in this setup, are also suitable in the automotive (electric and hybrid vehicle) applications [18].

The control algorithm's digitalization is described in [21-28] where the authors put much enthusiasm in research into FPGA's and DSP's implementation. The authors in [21-23] describe the measurement methods based on VCO and authors in [24-28] focus on control. Almost all published algorithms are based mainly on instantaneous current measurements and prediction strategy. In order to perform current-mode control, the inductor current is sampled using A/D converters, as is discussed in [29]. Such current measurement method is subject to disturbances that may arise when measuring instantaneous inductor-current signals. Only a few authors, [30] and [31], describe the average current measurement principles by using VCOs, but they did not realise the necessity of transferring the current reference values in the area space. However, disturbances can result in poor control and, thus, can distort the testing results.

The digitalization principle based on the measurement of the voltage and current integral values is explored in the following text. The integral value measurements are performed using VCOs and digital counters.

The operation of the BM DC-DC converter has to be both fast and precise, for which the current mode operation is a very appropriate option. Namely, the testing system should not introduce significant disturbances into the system and should behave as much as possible as an actual source to be connected to the powertrain DC-link and actual load to be applied to the powertrain shaft. Thus, the current control scheme is proposed, with the compensating ramp and dynamic reference, improved with the use of a PI compensator.

The four-leg bidirectional DC-DC converter, featured in Figure 2, is used with the basic control principle presented in Figure 3. Transistors in the same converter leg are switched on and off synchronously, one at a time with the dead-time insertion (both transistors switched off for a short period of time during the transition). Bidirectional power flow is enabled, and the FPGA is used as a control device on which the control featured in Figure 3 is applied. The converter can operate either as a voltage or current source. Cascade control is used, with the inner loop using the current-programmed mode controllers (CPC in Figure 3), which are used to control the inductor currents $i_{L 1}, i_{L 2}, i_{L 3}$, and $i_{L 4}$. The reference value of the inductor current $i_{r e f}$ is the same for all inductor currents. The outer loop enables improved current control or voltage control in buck or boost operation mode. In the outer control loop, a PI controller (compensator) is used for all modes of operation. In the case of required precise current control, an additional current control loop is used, due to the fact that with 
using only a current-programmed mode a static error appears. Measurements are performed using VCOs. Bidirectional DC-DC was designed to enable testing of Voltage Source Inverter and Current Source Inverter devices, but it should also be possible to use it for testing of the Multilevel Inverters. Reference values $V_{R E F}$ can be set for input voltage $V_{d}$ or output voltage $V_{0}$, whereas current reference $I_{R E F}$ can be set for the total inductor current $\left(I_{L}=i_{L 1}+i_{L 2}+i_{L 3}+i_{L 4}\right)$.

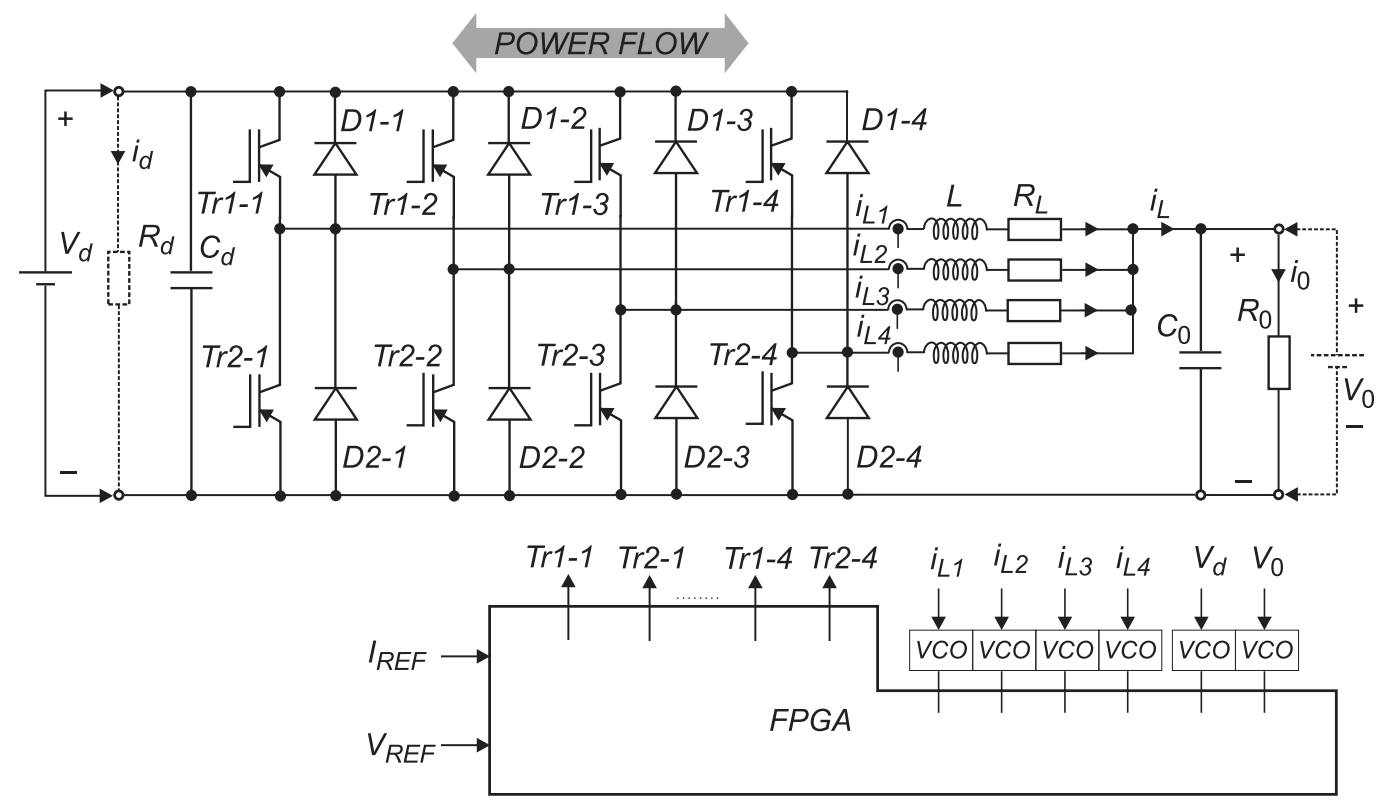

Figure 2. Four-leg bidirectional DC-DC converter scheme.

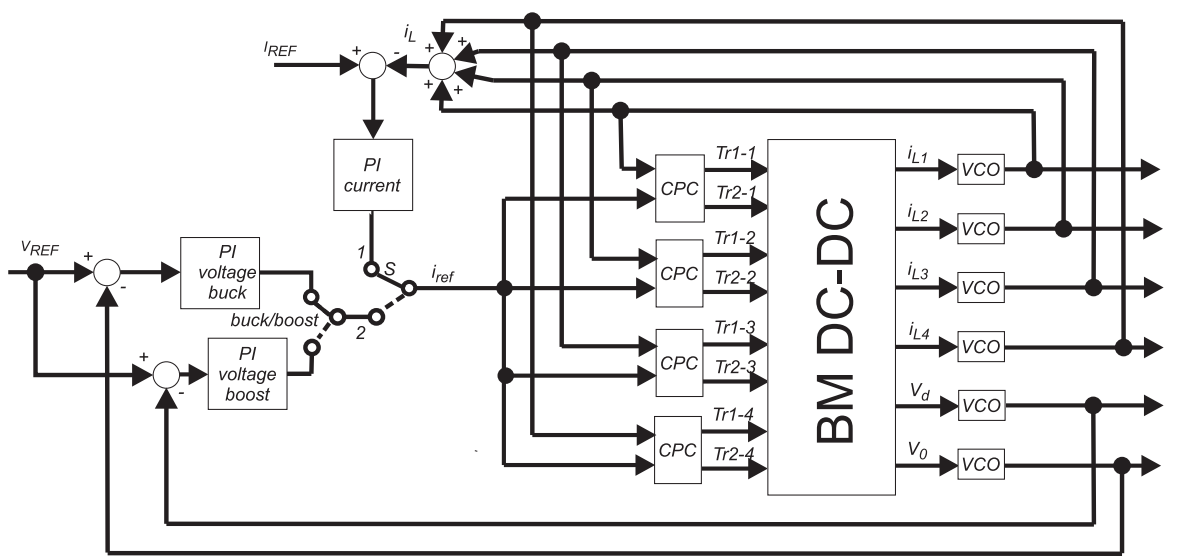

Figure 3. Control principle.

The main contribution of the paper is the presented method using VCOs for the measurements of currents and voltages and use of integrals from VCOs for the current reference shaping. Bidirectional control of current and voltage is possible, which enables the operation as voltage or current source. Because the integral measurement method had to be tested and evaluated, the power rate was chosen to be up to $6 \mathrm{~kW}$ in order to enable safer experimentation. The presented BM DC-DC setup was used for the proof of concept, whereas the high power real system will be built in the future, based on the obtained results.

The paper is organised as follows. Section 1 gives an introduction of the testing requirements, principles and equipment in the automotive industry. The need for the use of bidirectional multiphase DC-DC converters is presented, as well as some requirements regarding their operation. Section 2 describes the operating principle of the converter, mathematical background of the measurement 
principle, and mathematical integration using VCO and counter. Frequency characteristics of current and voltage are presented, together with the VCO static characteristics. Dynamic reference calculation is also explained. Simulation and experimental results are presented in Section 3. The experimental setup is presented and the test-bench system with FPGA implementation is described. Control scheme modelling is incorporated in this section in order to give an explanation of the operation, methods and parameters chosen. Modelling is considered based on the PWM switching approach [32-34]. Much of the analysis performed here is an extension of well-known modelling methods. The control scheme is modelled and transfer functions are presented. The main reason why it is applied is to show that this modelling method is also appropriate for such an organised control approach. The control principle is applied on a four-phase BM DC-DC converter tested up to $6 \mathrm{~kW}$. This section also includes the experimental results for current and voltage control in buck and boost operation. Section 4 concludes the paper.

\section{VCO Measurement Principle and Dynamic Reference Calculation}

Six A/D conversions (four for currents and two for voltages) of the measured signals are required for the voltage and current mode control of a BM DC-DC converter, as shown in Figure 2. The measurement chain for inductor currents, input and output voltages is presented in Figure 4, whereas pulse triggering, measurement and dynamic reference are featured in Figure 5. Detailed current and voltage control scheme is presented in Figure 6.

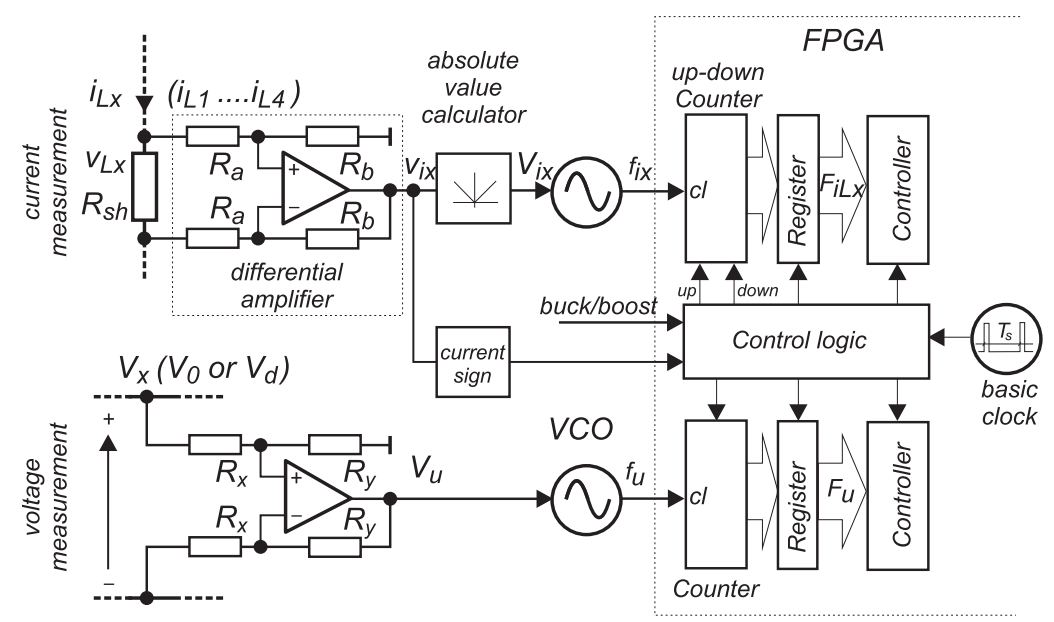

Figure 4. Measurement chain for inductor-currents $\left(i_{L 1} \ldots i_{L 4}\right)$, input and output voltages $\left(V_{0}\right.$ and $\left.V_{d}\right)$ performed by VCO.

The time-based A/D converter uses a VCO where the frequency $f_{v c o}$ is controlled by the input voltage $V_{i n}$ (Figure 4). The VCO output $F\left(F_{i L x}\right.$ or $F_{u}$ in Figure 4$)$ is proportional to the time integral of the applied input voltage during the sampling period, and can be described by:

$$
F=\int_{t_{s 1}}^{t_{s 2}} f_{v c o} d t=\int_{t_{s 1}}^{t_{s 2}}\left(k_{v c o} V_{i n}(t)+f_{0}\right) d t,
$$

where the $k_{v c o}[\mathrm{~Hz} / \mathrm{V}]$ and $f_{0}$ are VCO gain and free-running frequency when $V_{\text {in }}=0 \mathrm{~V}$, respectively (for chosen $\mathrm{VCO} k_{v c o}=44.1 \mathrm{MHz} / \mathrm{V}, f_{0}=23.5 \mathrm{MHz}$ ). $t_{s 1}$ and $t_{s 2}$ are integration limits representing the limits of the measurement interval. Based on nomenclatures used in Figure 4, voltage $V_{i n}$ corresponds with current information $V_{i x}=\left|v_{i x}\right|$ and voltage information $V_{u}$, respectively. $i_{L x}$ is the representation of the phase current $i_{L 1}, i_{L 2}, i_{L 3}$ or $i_{L 4}$ (in the presented case, the voltage drop on shunt is measured). In the case of voltage measurement, $V_{x}$ represents the input voltage $V_{d}$ or output 
voltage $V_{0}$. The resulting VCO output is the clock input $(\mathrm{cl})$ of the Counter and integration is started (Counter starts counting) at the time instance of transistor turn-on $t_{s 1}$. The Counter output is forwarded to the Register at the time instance $t_{s 2}$, when the information about the calculated area $F(t)$ (integral representing the average value multiplied by sampling time interval $T_{s}\left(T_{S}=40 \mu \mathrm{s}\right)$ ) of the inductor current or voltage are available for further utilization.

The resolution of the described A/D conversion can be adjusted by choosing the minimal and maximal frequency of VCO. Twelve-bit resolution was selected in the presented case.

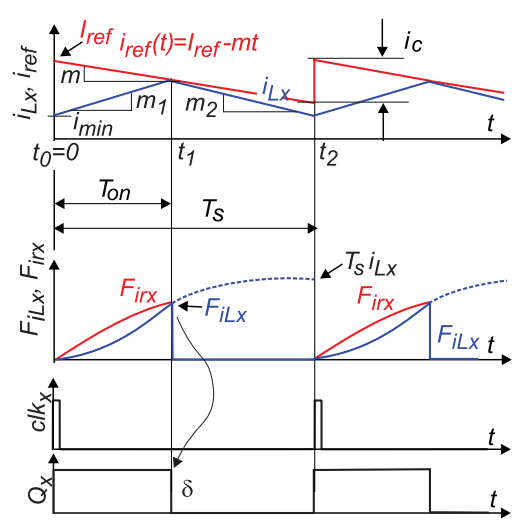

(a)

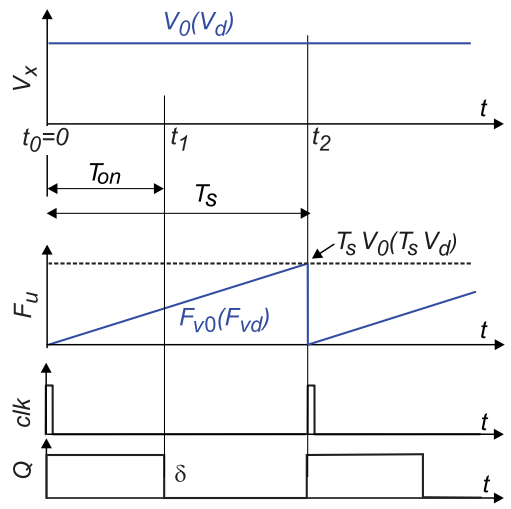

(b)

Figure 5. Current-Programmed Control Mode using VCOs; (a) current measurement, dynamic reference and triggering pulse generation; (b) voltage measurement.

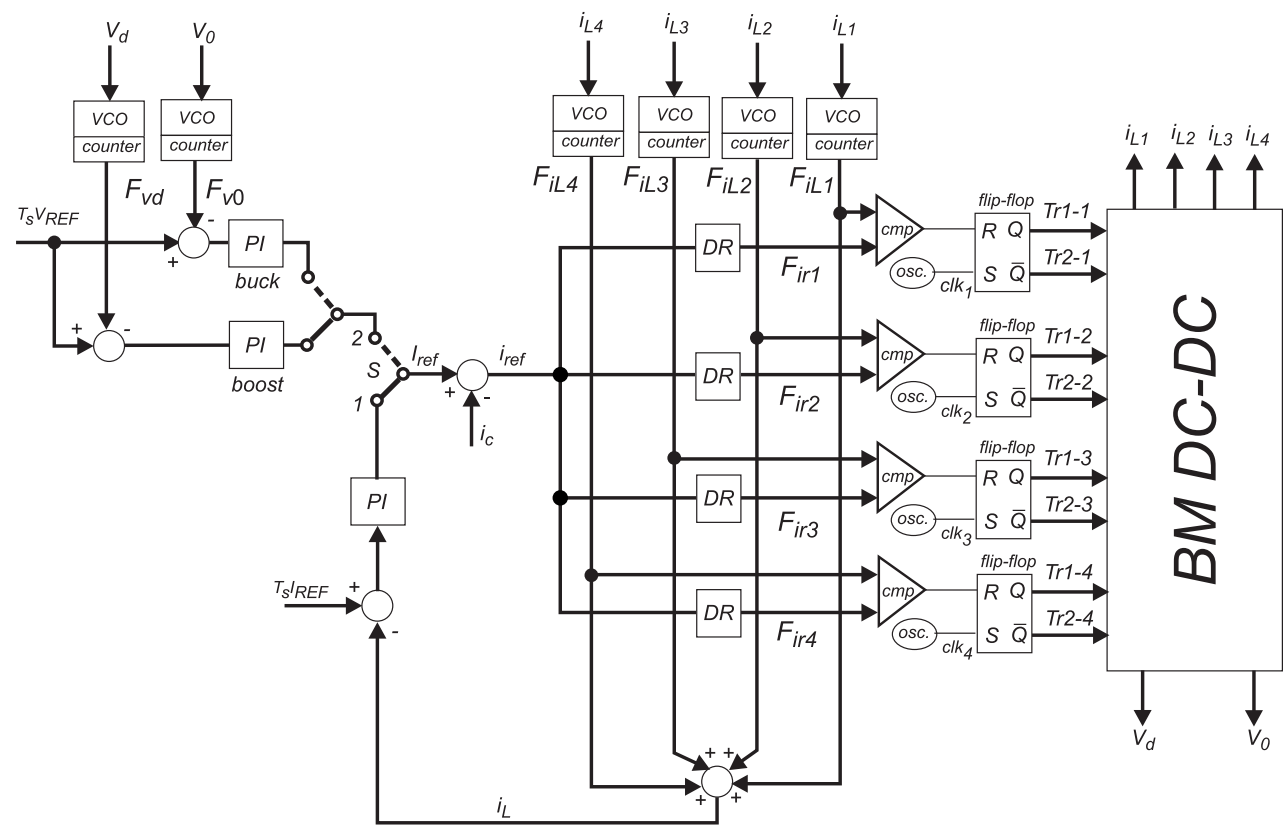

Figure 6. Detailed current and voltage control scheme; the current modulator with Dynamic Reference and Compensating Ramp.

\subsection{Analysis of Current and Voltage-Measurements}

The current measurement chain consists of a differential amplifier, absolute value calculator and VCO for analogue signal acquisition (see Figure 4). The power-flow direction is defined by logic signal buck/boost. For example, in the buck mode operation, the current through shunt resistor $R_{\text {sh }}$ is positive and the VCO and integration processes (described below) are working properly. Due to 
the synchronous switch operation (instead of diode, the transistor is switched-on), the conversion is always in the Continuous Current Mode (CCM) of operation, so, during the low current operations, the current also has the negative instantaneous value, and, due to the use of an absolute value calculator, the integration performed by up-down Counter would calculate the wrong integration results.

By appropriate use of the signals up and down, the integral value in the up-down Counter will be correct. As follows from Equation (1) and Figure 4, for the inductor current $i_{L x}$, measurement is performed through the voltage drop on the shunt resistor $V_{L x}=R_{s h} i_{L x}$. On the VCO input, the voltage $V_{i x}=\left|v_{i x}\right|=R_{b} R_{s h} / R_{a}\left|i_{L x}\right|=k_{i L}\left|i_{L x}\right|\left(k_{i L}=R_{b} R_{s h} / R a, R_{b} / R_{a}=18, R_{s h}=0.02 \Omega\right)$ appears ( $k_{i L}$ represents the inductor current VCO gain). The instantaneous VCO frequency $\left(f_{v c o}\right)$ for inductor current $\left(f_{i x}\right)$ is calculated from:

$$
f_{i x}=k_{v c o} v_{i x}(\tau)+f_{0} ; \text { when } \tau \in\left(t_{0}, t_{1}\right),
$$

where $t_{0}$ and $t_{1}$ (shown in Figure 5) correspond with $t_{s 1}$ and $t_{s 2}$ indicated in Equation (1), respectively. Presuming that inductor resistance $R_{L}$ can be neglected, the current $i_{L x}$ can be expressed with:

$$
V_{i x}(\tau)=k_{i L}\left(i_{\min }+m_{1} \tau\right) ; \text { when } \tau \in\left(t_{0}, t_{1}\right),
$$

where $t_{0}=0, i_{\min }=i_{L x}\left(t_{0}\right)$, and coefficient $m_{1}$, the inductor current slope during the switch-ON state, depends on the circuit parameters, in the case of the buck converter $m_{1}=\left(V_{d}-V_{0}\right) / L$ (and in the case of the boost converter $\left.m_{1}=V_{0} / \mathrm{L}\right)\left(V_{d}=400 \mathrm{~V}, V_{0}=200 \mathrm{~V}, L=620 \mu \mathrm{H}\right) . L$ is the inductor phase inductance. After using Equations (1)-(3), it follows:

$$
F_{i L x}(t)=\frac{k_{i L} m_{1}}{2} t^{2}+\left(f_{0}+k_{i L} i_{\min }\right) t ; \text { when } t \in\left(0, t_{1}\right) .
$$

As has been already mentioned above, the up-down counter is used for the current measurement. Therefore, the input of the VCO, $V_{i x}$, in this case, is actually the absolute value of the inductor current, and the current sign determines the direction of counting (taking into account the operation mode, buck or boost).

Figure 5 a features the measurement of inductor current and dynamic reference shaping. The top graph presents the inductor current $\left(i_{L x}\right)$ and reference slope $i_{\text {ref }}$. The integral current and its reference in area space are presented in the second graph, the third graph features the trigger signal $c l k_{x}$ for VCO counting, whereas the bottom graph presents the state of transistor $\left(Q_{x}\right)$.

Again regarding Equation (1) and Figure 4 for the voltage (output or input, $V_{x}=V_{0}$ or $V_{x}=V_{d}$ ) measurement, the instantaneous VCO frequency $\left(f_{v c o}\right)$ for voltages $\left(f_{u}\right)$ is calculated from:

$$
f_{u}=k_{V x} V_{x}(\tau)+f_{0} ; \text { when } \tau \in\left(t_{0}, t_{2}\right),
$$

where the input or output voltage $V_{x}\left(V_{d}\right.$ or $\left.V_{o}\right)$ is multiplied by voltage VCO gain $k_{V x}\left(k_{V x}=\right.$ $\left.k_{v c o} A_{v}, A_{v}=R_{y} / R_{x}\right)\left(A_{v}=R_{y} / R_{x}=6 \times 10^{-3}\right)$.

The voltage integral is measured during the integration interval $T_{s}\left(T_{s}=t_{2}-t_{0}, t_{0}=0\right)$. Input/output voltage $V_{x}$ can be considered constant (due to the bulk capacitors $C_{d}$ or $C_{0}$ ) within the integration interval. For the input voltage, it follows that:

$$
V_{x}=V_{d}
$$

By using Equations (5) and (6), the input voltage integral is evaluated as follows:

$$
F_{v d}(t)=V_{d} t ; \text { when } t \in\left(0, t_{2}\right) .
$$


As indicated in Equation (7), the area $F_{u}$ is time dependent, and, at the end of the integration interval, when $t=t_{2}=T_{s}$, it follows that:

$$
F_{v d}=V_{d} T_{s}
$$

Following the same procedure, the output voltage can be expressed as:

$$
F_{v 0}=V_{0} T_{s}
$$

Voltage measurement is presented in Figure $5 \mathrm{~b}$. The top graph presents the measured voltage $\left(V_{0}\right.$ or $\left.V_{d}\right)$, voltage VCO output $\left(F_{v 0}\right.$ or $\left.F_{v d}\right)$ is presented in the second graph, whereas the third and bottom graphs feature the trigger signal $c l k$ for VCO counting and the state of transistor $(Q)$ to which the voltage measurement is aligned, respectively.

\subsection{Bandwidth of the Current and Voltage Measurement Chain}

The bandwidth of analogue acquisition of current and voltage measurement circuits shown in Figure 4 needs to be taken into account. During the development phase, the Hall current sensors have been considered, but, due to their limited bandwidth, the setup using a shunt resistor and differential operational amplifier was chosen [35]. In a current measurement-chain, the absolute value is obtained by using the two diode-equipped operational amplifiers' circuit as suggested in [36]. According to the proposed differential amplifier scheme shown in Figure 4, the equation to be applied for the current closed-loop frequency characteristics is:

$$
G_{i}(j \omega)=\frac{R_{b}}{R_{a}} \frac{1}{1+\left(1+\frac{R_{b}}{R_{a}}\right) \frac{1}{A(j \omega)}},
$$

where the frequency dependent gain of the internally compensated operational amplifier is:

$$
A(j \omega)=\frac{A_{0}}{1+\frac{j \omega}{\omega_{t} / A_{0}}}=\frac{A_{0}}{1+\frac{j \omega}{\omega_{b}}} .
$$

$A_{0}$ is the open-loop gain of the amplifier at the frequency $f=\omega /(2 \pi)=0 \mathrm{~Hz}$, which is usually a high number $\left(10^{4}\right.$ to $\left.10^{6}\right), \omega_{t}$ represents the cross-over frequency at unity open-loop gain $(|A(j \omega)|=$ 1 or $0 \mathrm{~dB}$ ), and $\omega_{b}$ is the frequency where the open-loop gain of the operational amplifier is decreased by $3 \mathrm{~dB}\left(\omega_{b}=\omega_{t} / A_{0}\right)$. By performing an analysis using Equations (10) and (11), assuming that $A_{0} \gg R_{b} / R_{a}$, the closed-loop frequency characteristic for the inductor current measurement circuit can be evaluated as:

$$
G_{i}(j \omega) \cong \frac{G_{i o}}{1+\frac{j \omega}{\omega_{b i}}}
$$

where $G_{i o}=R_{b} / R_{a}$ represents the closed-loop gain of the inductor current measurement circuit up to frequency $f_{b i}\left(f_{b i}=\frac{\omega_{b i}}{2 \pi}, \omega_{b i}=\frac{\omega_{t}}{1+R_{b} / R_{a}}\right)$. The same procedure can be used for the voltage measurement-chain. The closed-loop frequency characteristics for the voltage measurement circuit are:

$$
G_{v}(j \omega) \cong \frac{G_{v o}}{1+\frac{j \omega}{\omega_{b v}}},
$$

where $G_{v o}=R_{y} / R_{x}$ represents the closed-loop gain up to frequency $f_{b v}\left(f_{b v}=\frac{\omega_{b v}}{2 \pi}, \omega_{b v}=\frac{\omega_{t}}{1+R_{y} / R_{x}}\right)$.

Corresponding frequency characteristics are shown in Figure 7a, where the bandwidths of current and voltage measurement chain are shown. The operational amplifier LMH6611 [35] was used for the current and voltage measurement circuit. 


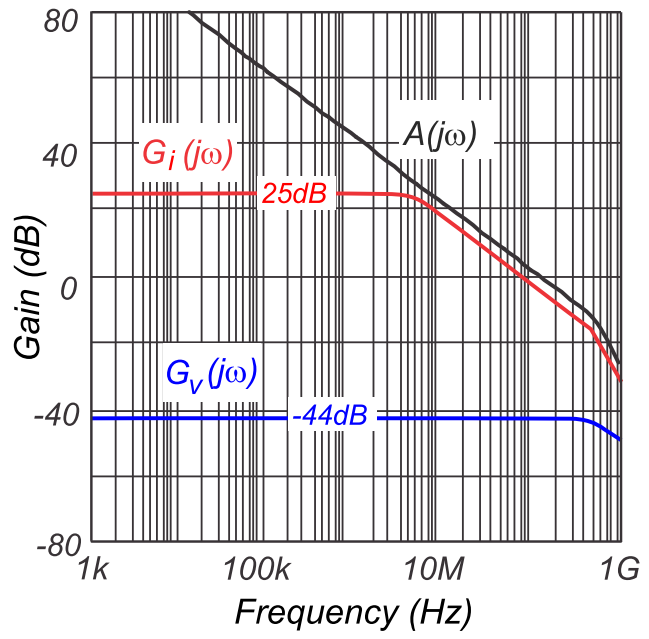

(a)

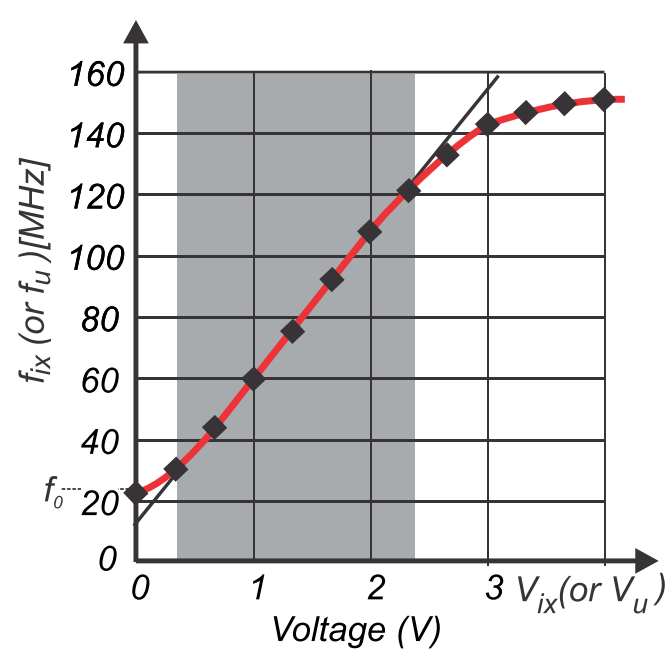

(b)

Figure 7. (a) Frequency characteristic of open-loop gain for LMH6611 (black line), inductor current measurement circuit (red line) and voltage measurement chain (blue line); (b) Measured VCO static characteristic.

The absolute value calculator (Figure 4) is designed to operate as a proportional amplifier with unity gain $(0 \mathrm{~dB})$ and with such a bandwidth that does not interfere with the design process of the controllers (it will be described in Section 3). The next component that appears in a current and voltage measured-chain is the VCO, which is also considered as a proportional gain. The measured static characteristic is shown in Figure 7b. Only the linear part of characteristics is used for the measurement procedure in the described application. The design parameters of analogue acquisition systems satisfy the condition:

$$
\omega_{b v}>\omega_{b i} \gg \frac{1}{\sqrt{L C}},
$$

where $L$ and $C$ represent the inductance and capacitance appearing in the control process.

\subsection{The Inductor Current Dynamic Reference (DR)}

Because the area (integral) $F_{i L x}$ is time dependent, the current reference $i_{\text {ref }}$ should also be expressed in the area space as follows:

$$
F_{i r x}(t)=\int_{0}^{t} i_{r e f}(\tau) d \tau .
$$

Such current reference enables the control of peak-inductor-current known from the analogue approach [37]. The current reference shaping is indicated and performed in block DR (Dynamic Reference; Figure 6). When the peak-inductor-current-programmed control is used, the subharmonic oscillation always appears when the duty-cycle function value $\delta$ exceeds 0.5 (average value of $\delta$ is $\Delta_{p}=T_{o n} / T_{s}>0.5, T_{o n}$ is the duration of the switch-ON state) [34]. In order to avoid this instability, a Compensating Ramp (CR) is introduced, as was suggested in [34]. This CR is taken into account in DR calculation, as follows:

$$
i_{r e f}(t)=I_{r e f}-i_{c}
$$


where $i_{c}=m t$ and $m$ is a CR slope $\left(m=I_{c} / T_{s}\right), I_{r e f}$ is the reference inductor current (from outer control loop) and the DR is obtained after using Equation (15), as follows:

$$
F_{i r x}(t)=I_{r e f} t-\frac{m}{2} t^{2}
$$

As is presented in Figure 6, $F_{i r x}$ is calculated for each of the phase currents.

With the use of DR and CR, the peak current mode can be achieved without subharmonic oscillation. The measured inductor current is used in order to achieve the current-programmed control mode of converter operation because the algorithm enables the switching action inside the $T_{s}$. DR and $\mathrm{CR}$ are featured in Figure 5, together with the current measurement.

\section{Simulation and Experimentation}

For simulation and experimental purposes, the current-programmed mode control was modelled in s-space (as transfer functions), in order to design the CR slope and current or voltage compensating circuits (PI compensator). Simulations and experiments were performed on the basis of the experimental setup presented in Figure 8. The parameters of the experimental system are featured in Table 1. $R_{0}$ and $R_{d}$ represent the load (applied in simulations and experiments) for buck and boost operation, respectively. $L_{1 t o 4}$ are the inductances of inductors $\left(L_{1}=L_{2}=L_{3}=L_{4}=L\right), C_{0}$ is the output and $C_{d}$ input inductance (Figure 2). In order to explore the described measurement principle, the parameters for analogue signal acquisition (Section 2.2) must satisfy condition in Equation (14), so this simplifies the controller design.

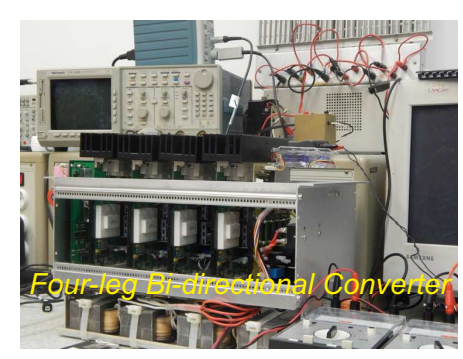

(a)

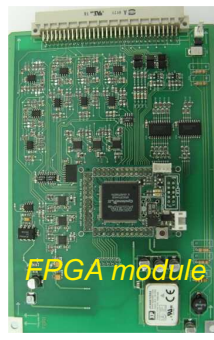

(b)

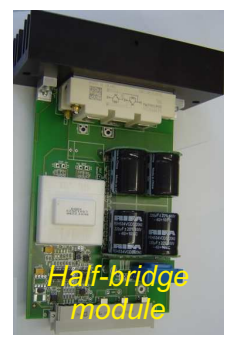

(c)

Figure 8. Experimental setup; (a) interleaving DC-DC buck and boost converter; (b) FPGA board; (c) half-bridge module.

Table 1. Simulation and experimental parameters.

\begin{tabular}{ccccc}
\hline Buck Conversion & \multicolumn{1}{l}{} \\
\hline Input & Output & Load & & \\
\hline $\begin{array}{c}V_{d} \\
\text { up to } 500 \mathrm{~V}\end{array}$ & 200 to $300 \mathrm{~V}$ & $14.6 \Omega(9.5 \Omega)$ & $620 \mu \mathrm{H}$ & $880 \mu \mathrm{F}$ \\
\hline Boost Conversion & \multicolumn{1}{c}{$R_{0}$} & & \\
\hline Input & Output & Load & & \\
\hline$V_{0}$ & $V_{d}$ & $R_{d}$ & $L_{1}$ to 4 & $C_{d}$ \\
up to $300 \mathrm{~V}$ & 350 to $500 \mathrm{~V}$ & $60 \Omega(30 \Omega)$ & $620 \mu \mathrm{H}$ & $880 \mu \mathrm{F}$ \\
\hline
\end{tabular}

\subsection{Control Scheme Model}

In order to apply the current-programmed mode control principle, the appropriate BM DC-DC converter model was investigated as suggested in [32-34,37]. Figure 9 features the small-signal current programmed model of the applied control scheme [37], where $\sim$ indicates the small-signal value 
(variation from the average value). $\widetilde{v}_{g}$ represents the voltage input, $\widetilde{i}_{L x}$ the current output and $\widetilde{v}_{x}$ the voltage output. $\widetilde{\delta}$ is the duty cycle variation, $\widetilde{e}$ the current control error, and $\widetilde{i}_{\text {ref }}$ is the current reference variation (inner control loop). $\widetilde{V}_{r e f}$ and $\widetilde{I}_{r e f}$ represent the reference values' variation for voltage and current (outer control loop), respectively. $\widetilde{I}_{\text {ref }}$ actually represents the single phase current reference, which is due to the simpler representation of the control design.

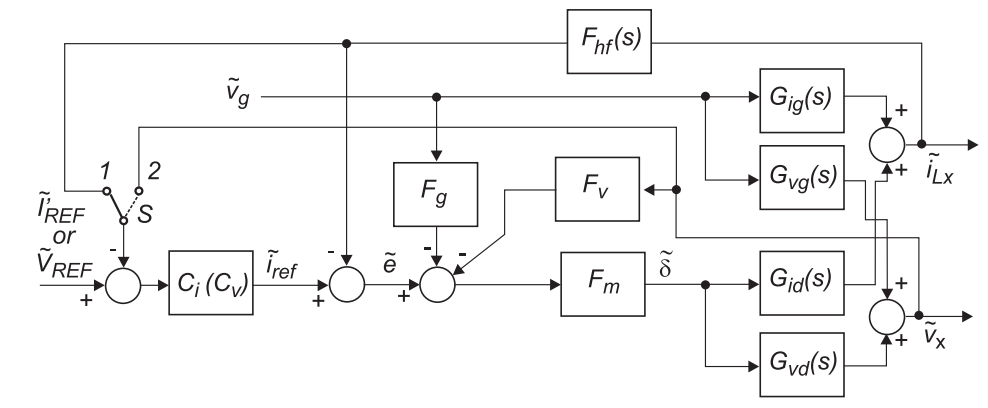

Figure 9. Block diagram of the BM DC-DC converter control scheme.

Current-programmed controller gains $F_{g}$ (input-voltage-to-control gain), $F_{v}$ (output-voltage-to-control gain) and $F_{m}$ (modulation gain) are presented in Table 2, and the transfer functions necessary for control parameter design, $G_{v d}(s)$ (duty-cycle-to-voltage-output transfer function), $G_{i d}(s)$ (duty-cycle-to-current-output transfer function), $G_{v g}(s)$ (voltage-input-to-voltage-output transfer function) and $G_{i g}(s)$ (voltage-input-to-current-output transfer function), are presented in Table 3. $V_{d}, V_{0}$ and $\Delta_{p}$ in Tables 2 and 3 represent the average values of input voltage, output voltage and duty cycle, respectively $\left(R_{0}=14.6 \Omega, R_{d}=60 \Omega, V_{0}=200 \mathrm{~V}, V_{d}=400 \mathrm{~V}\right)$. An external control loop can be applied in order to either improve the current control or add the voltage control. PI compensators $C_{i}$ and $C_{v}$ are used for that purpose. $C_{i}$ can be used as an additional current controller, whereas $C_{v}$ can be applied as an input or output voltage controller.

Table 2. Current programmed controller gains.

\begin{tabular}{ccc}
\hline & $\boldsymbol{F}_{\boldsymbol{g}}$ & $\boldsymbol{F}_{\boldsymbol{v}}$ \\
\hline Buck & $\frac{\Delta_{p}^{2} T_{s}}{2 L}$ & $\frac{\left(1-2 \Delta_{p}\right) T_{s}}{2 L}$ \\
\hline Boost & $\frac{\left(2 \Delta_{p}-1\right) T_{s}}{2 L}$ & $\frac{\left(1-\Delta_{p}\right)^{2} T_{s}}{2 L}$ \\
\hline$F_{m}$ & $\frac{1}{\left(m+\Delta_{p} m_{1}-\Delta_{p}^{\prime} m_{2}\right) T_{s}}$, & $\Delta_{p}^{\prime}=1-\Delta_{p}$ \\
\hline
\end{tabular}

Table 3. Transfer functions (small-signal model).

\begin{tabular}{cccc}
\hline Buck & & & \\
\hline$G_{v d}(s)$ & $G_{i d}(s)$ & $G_{v g}(s)$ & $G_{i g}(s)$ \\
\hline$\frac{V_{0}}{\Delta_{p} d_{a}(s)}$ & $\frac{V_{0}\left(1+s R_{0} C_{0}\right)}{R_{0} \Delta_{p} d_{a}(s)}$ & $\frac{\Delta_{p}}{d_{a}(s)}$ & $\frac{\Delta_{p}\left(1+s R_{0} C_{0}\right)}{R_{0} d_{a}(s)}$ \\
\hline$d_{a}(s)$ & $1+s \frac{L}{R_{0}}+s^{2} L C_{0}$ & & \\
\hline Boost & & & \\
\hline$G_{v d}(s)$ & $G_{i d}(s)$ & $G_{v g}(s)$ & $G_{i g}(s)$ \\
\hline$\frac{V_{d}-\frac{s V_{d}}{R_{d} \Delta p^{\prime 2}}}{\Delta_{p}^{\prime} d_{b}(s)}$ & $\frac{2 V_{d}\left(1+s \frac{R_{d} C_{d}}{2}\right)}{R_{d} \Delta_{p}^{\prime 2} d_{b}(s)}$ & $\frac{1}{\Delta_{p}^{\prime} d_{b}(s)}$ & $\frac{\left(1+s R_{d} C_{d}\right)}{R_{d} \Delta_{p}^{\prime 2} d_{b}(s)}$ \\
\hline$d_{b}(s)$ & $1+\frac{s L}{R_{d} \Delta_{p}^{\prime 2}}+\frac{s^{2} L C_{d}}{\Delta_{p}^{\prime 2}}$ & & \\
\hline
\end{tabular}


Instantaneous inductor current value is used in current-programmed mode control, which introduces a unique phenomenon, the so-called current mode phenomenon [34]. Namely, oscillations can occur at half the switching frequency, which cannot be modeled with an average model. In order to include these properties and, thus, provide an accurate current-programmed mode control model, a high-frequency term has to be considered and included into the feedback loop of inductor current. The second-order approximation of this behaviour (introduced in [34]), which can be derived directly from a discrete-time system representing the modulator feedback, is expressed by transfer function $F_{h f}(s)$ as follows:

$$
F_{h f}(s)=\frac{s T_{s}}{e^{s T_{s}}-1} \simeq \frac{s^{2}}{\omega_{n}^{2}}+\frac{s}{\omega_{n} Q_{z}}+1,
$$

where $Q_{z}=-2 / \pi$ and $\omega_{n}=\pi / T_{s}$. This approximation is capable of describing a current-mode phenomenon accurately with constant switching frequency operation up to half the switching frequency.

Based on the formulas in Tables 2 and 3, and the parameters presented in Table 1, the quantitative assessment of current-programmed mode control was performed trough frequency responses.

\subsection{Current-Programmed Control Transfer Function}

The frequency responses of continuous conduction mode operating buck and boost converters were modelled by using Tables 2 and 3 and Figure 9 .

The transfer function $\widetilde{i}_{L x}(s) / \widetilde{i}_{\text {ref }}(s)$ can be calculated from:

$$
F_{L R}(s)=\left.\frac{\widetilde{i}_{L}(s)}{\widetilde{i}_{r e f}(s)}\right|_{\widetilde{v}_{g}=0}=\frac{G_{i d}(s) F(s)}{1+G_{i d}(s) F(s) F_{h f}(s)},
$$

where:

$$
F(s)=\frac{\widetilde{\delta}(s)}{\widetilde{e}(s)}=\frac{F_{m}}{1+F_{v} G_{v d}(s) F_{m}} .
$$

Based on the parameters given in Table 1, the quantitative evaluation of compensating-ramp slope is done by using the open loop transfer function $\left(G_{i d}(s) F(s) F_{h f}(s)\right)$ for buck and boost converter operations. The frequency responses are shown in Figure 10a for buck and Figure 10b for boost operation. Magnified cut-outs at the critical frequency $f_{c r}$ are included in order to improve visibility. It is evident from the frequency responses that an instability will occur when $C R$ is not applied $\left(i_{c}=0 \mathrm{~A}\right.$, red curve, Equation (16)), due to the fact that the magnitude is higher than $0 d \mathrm{~B}$ when the phase is $180^{\circ}\left(\right.$ at $\left.f_{c r}\right)$. When the CR is added (the applied values are indicated in Figure 10a for buck and $\mathrm{b}$ for boost converter operation, blue curve), the magnitude of the frequency responses is reduced and stable operation can be expected (magnitude is lower than $0 \mathrm{~dB}$ when the phase is $180^{\circ}$ ). 


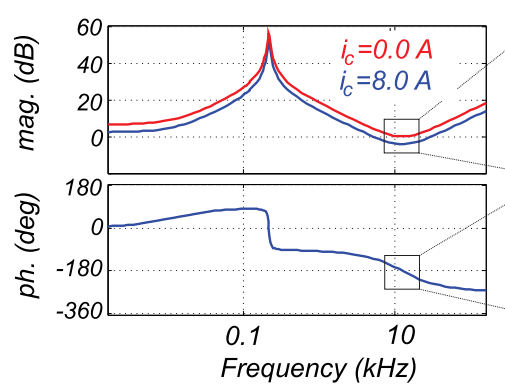

(a)

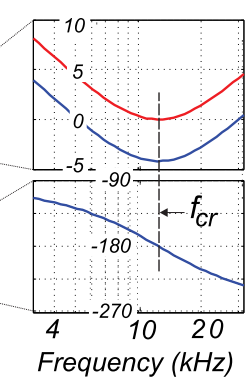

Frequency $(\mathrm{kHz})$

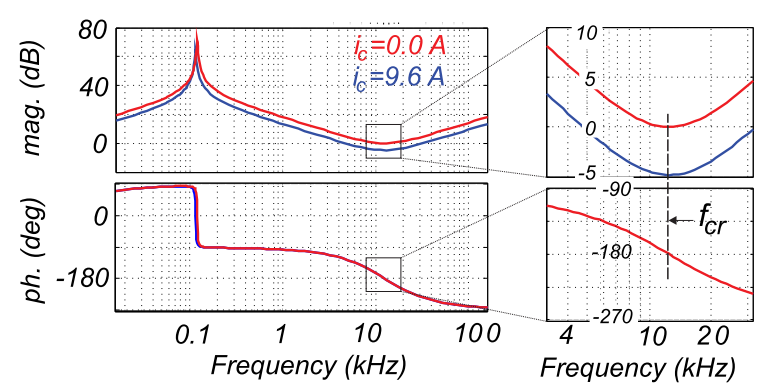

(b)

Figure 10. Frequency response, current-programmed mode control, for: (a) buck and (b) boost converter operation, without (red curve) and with (blue curve) compensating ramp.

Figure 11a shows the buck converter operations when applying constant peak-inductor-current control. Further analyses were performed when the load changed: $R_{0}=14.6 \Omega \rightarrow 9.5 \Omega \rightarrow 14.6 \Omega$. When the load is $R_{0}=14.6 \Omega$, the output voltage is more than $200 \mathrm{~V}$, thus the subharmonic oscillation in the currents is evident (inductor currents in the second cut-out of Figure 11a). When the load changes to $R_{0}=9.5 \Omega$, converter generates the output voltage lower than $200 \mathrm{~V}$ and subharmonic oscillations disappear. It is evident that the subharmonic oscillations appear when the duty-ratio was greater than 0.5. These oscillations were removed from the current responses when CR was applied. Figure $11 \mathrm{~b}$ (inductor currents in the second cut-out of Figure 11b) demonstrates that the inductor current was stabilised when CR was used. The applied CR is represented by the falling green curve touching the peak value of current $i_{L 1}$.

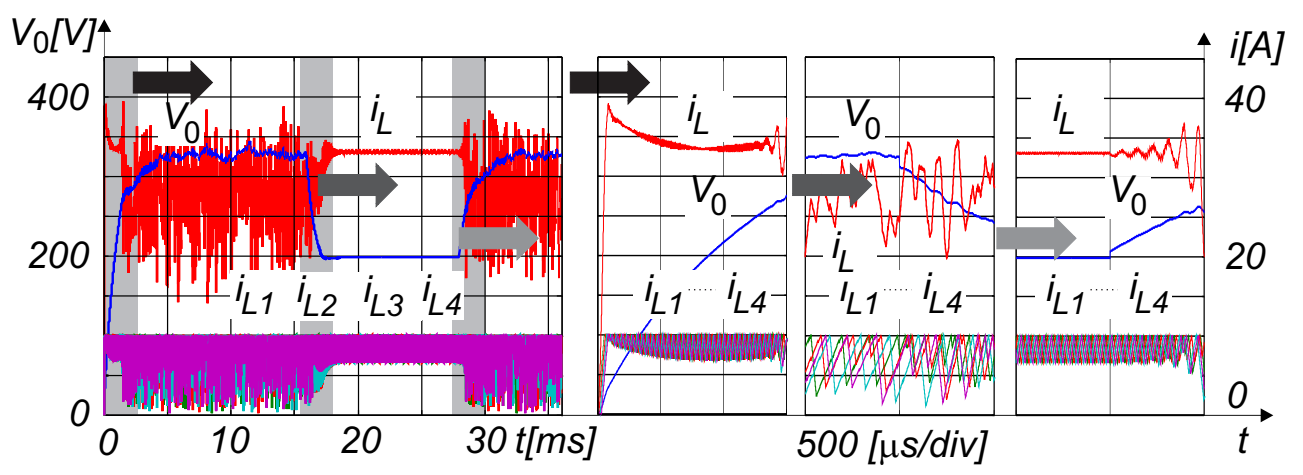

(a)

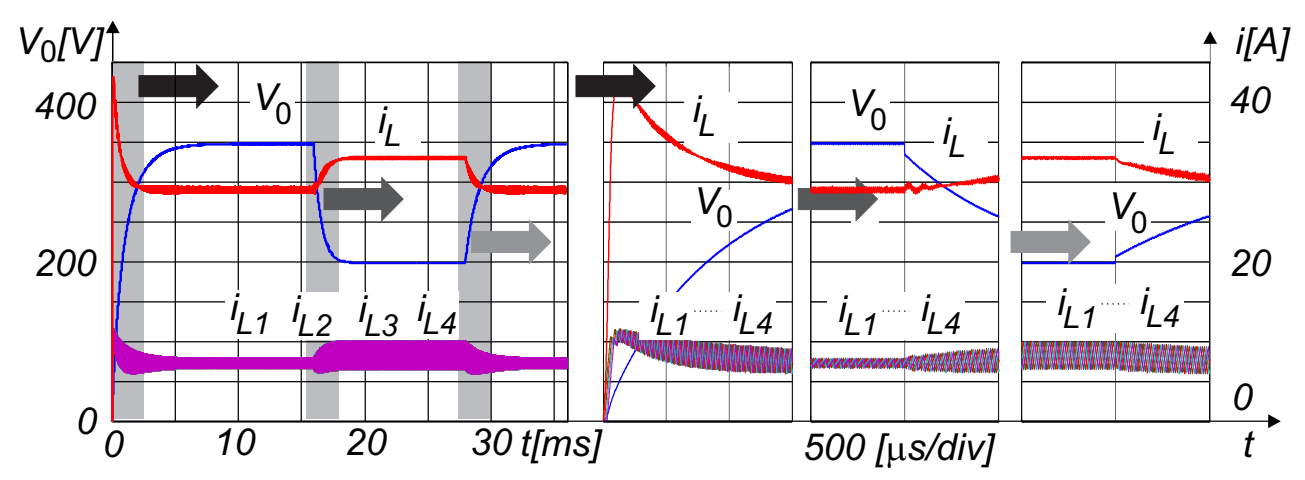

(b)

Figure 11. Simulation results, current-programmed mode control, buck-mode: (a) without CR; (b) with $\mathrm{CR} ; V_{0}$ (blue curve), $i_{L}$ (red curve), $i_{L 1}$ (green curve), $i_{L 2}$ (violet curve), $i_{L 3}$ (cyan curve), and $i_{L 4}$ (dark red curve). 
Simulation analysis for boost converter operation was also performed with changing load, $R_{d}=$ $60 \Omega \rightarrow 30 \Omega \rightarrow 60 \Omega$. Figure 12a shows the current-programmed mode control response when CR was not applied. The subharmonic oscillations are visible in the current response. When the load is $R_{d}=60 \Omega$, the output voltage is more than $400 \mathrm{~V}$ and subharmonic oscillations in the current appear (Figure 12a). The instability again (like in the buck operation mode) occurs when the duty-ratio exceeds $0.5\left(V_{d}>400 \mathrm{~V}\right)$. After introducing an appropriate compensating-ramp slope, which was designed using the frequency response featured in Figure 10b, the instability in the current response disappeared, as can be seen in Figure $12 \mathrm{~b}$.

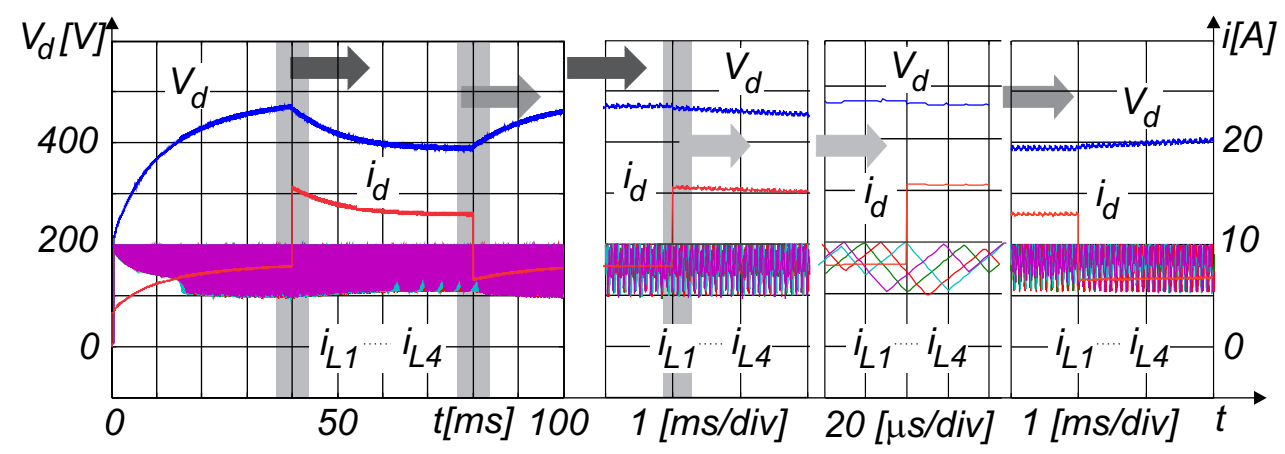

(a)

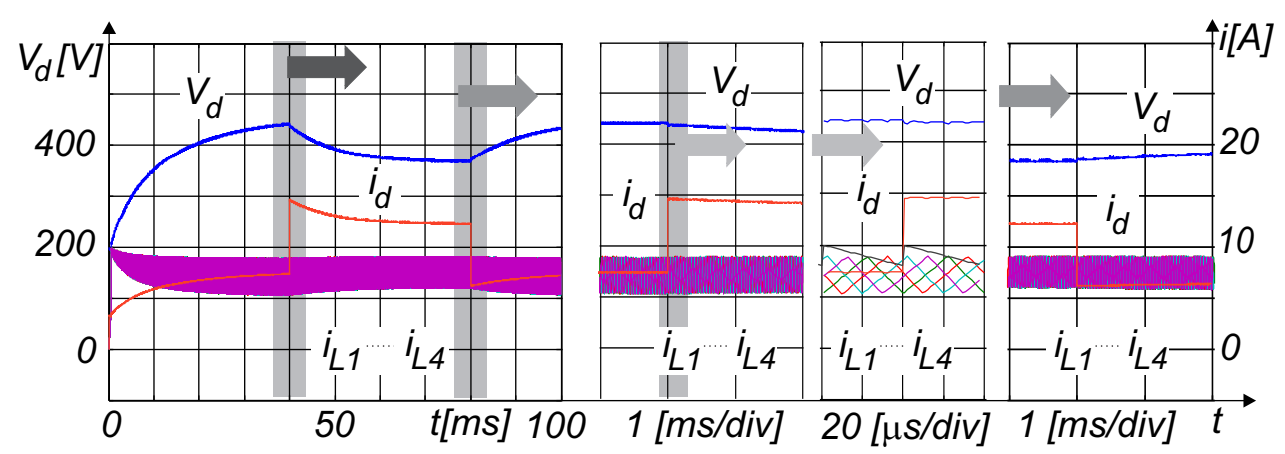

(b)

Figure 12. Simulation results, current-programmed mode control, boost mode: (a) without $C R ;(\mathbf{b})$ with $\mathrm{CR} ; V_{d}$ (blue curve), $i_{d}$ (red curve), $i_{L 1}$ (green curve), $i_{L 2}$ (violet curve), $i_{L 3}$ (cyan curve), and $i_{L 4}$ (dark red curve).

\subsection{Current Control with PI Compensator}

It can be observed from analysis that the static error appeared in current-programmed mode control. In the case when precise current control is required, the PI compensator can be used (Figure 9, switch $S$ in position 1) [38].

For the PI compensator parameter design, the transfer function $\widetilde{i}_{L x}(s) / \widetilde{I}_{R E F}(s)$ for a single phase current was derived by using Table 3 and Figure 9 as follows:

$$
\left.\frac{\widetilde{i}_{L}(s)}{\widetilde{I}_{R E F}^{\prime}(s)}\right|_{\widetilde{v}_{g}=0}=\frac{G_{i d}(s) F(s) C_{i}(s)}{1+G_{i d}(s) F(s) F_{h f}(s)\left(1+C_{i}(s)\right)},
$$

where the current controller $C_{i}$ is represented with the transfer function $C_{i}(s)=K_{i} \frac{s T_{i}+1}{s T_{i}}$. The parameters $K_{i}$ and $T_{i}$ (PI compensator gain and time constant, respectively) were evaluated using the open loop transfer function extracted from Equation (21) as $G_{i d}(s) F(s) F_{h f}(s)\left(1+C_{i}(s)\right)$. Because the parameters were calculated for the phase current, the output of the controller or the controller gain had to be divided by the number of phases in the simulations and experiments. The design of the 
controller was performed using frequency response (Bode plots). Open loop transfer function was used and first the phase margin was chosen. The time constant of the PI compensator was determined from the Bode plot and, finally, the a PI compensator gain was determined.

Figure 13a,b feature the frequency responses for PI compensator parameter design. It can be observed that the open loop transfer function magnitude is lower than $0 \mathrm{~dB}$ when the phase is $180^{\circ}$ for both, buck and boost operation mode. The obtained parameters $\left(K_{i}=0.25, T_{i}=0.24 \mathrm{~ms}\right.$, for buck and $K_{i}=0.35, T_{i}=0.24 \mathrm{~ms}$ boost operation) were used for simulation and experimentation. The current compensator transfer function is featured on the Bode plots as a reference, to show the impact of the PI compensator on the phase and magnitude. Closed loop frequency response for current control with PI compensator with transfer function featured in Equation (21) is presented in Figure 14a,b. It confirms the stable operation for buck and boost operation and features the available control bandwidth. For the reference, the transfer function of the PI compensator is again featured in the Bode plots.

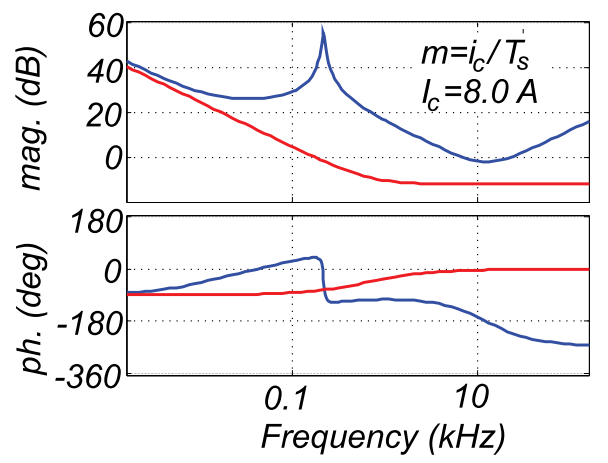

(a)

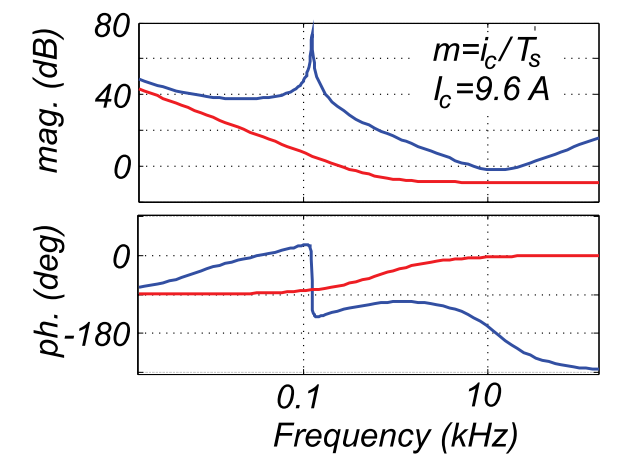

(b)

Figure 13. Frequency response, current control with PI compensator, $G_{i d}(s) F(s) F_{h f}(s)\left(1+C_{i}(s)\right)$ (blue curve) and $C_{i}(s)$ (red curve), for (a) buck controller design; (b) boost controller design.

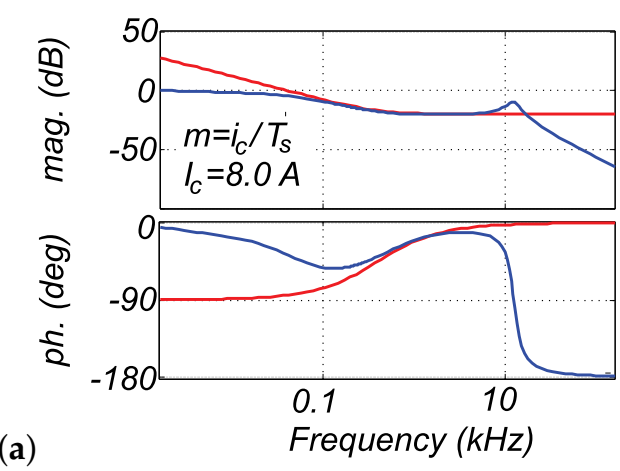

Figure 14. Frequency response, current control with PI compensator, closed loop (blue curve) and $C_{i}(s)$ (red curve), for (a) buck controller design; (b) boost controller design.

Figure $15 \mathrm{a}, \mathrm{b}$ represent the current response obtained by simulation, and Figure $16 \mathrm{a}, \mathrm{b}$ show the experimental results obtained under similar circumstances. 


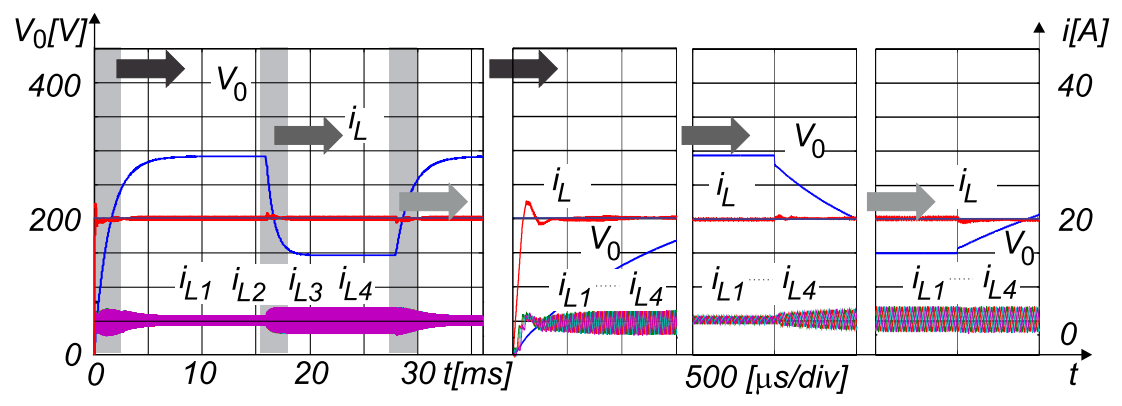

(a)

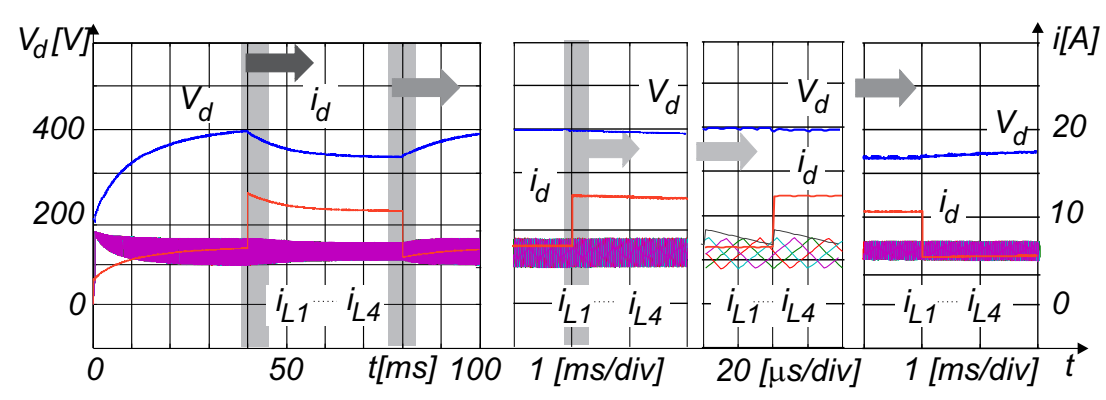

(b)

Figure 15. Simulation results, current control with PI compensator, with CR: (a) buck mode; (b) boost mode; voltage $V_{0}$ or $V_{d}$ (blue curve), current $i_{L}$ or $i_{d}$ (red curve), $i_{L 1}$ (green curve), $i_{L 2}$ (violet curve), $i_{L 3}$ (cyan curve), and $i_{L 4}$ (dark red curve).
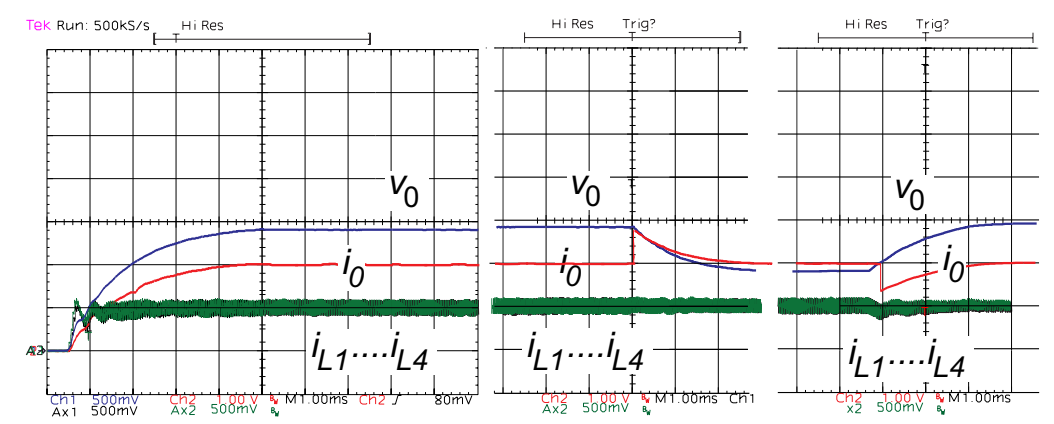

(a)
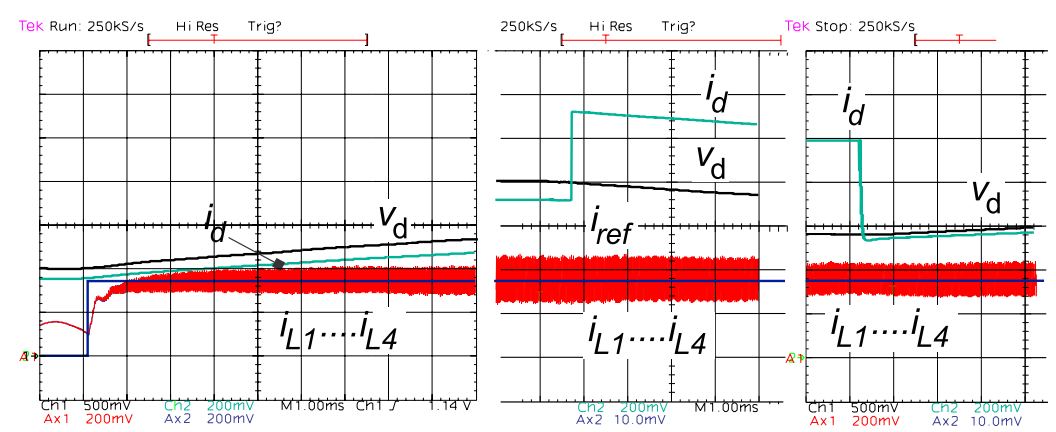

(b)

Figure 16. Experimental results, current control, with CR and PI compensator: (a) buck mode; $x$-axis, $1 \mathrm{~ms} /$ div, $y$-axis, $V_{0}, 100 \mathrm{~V} / \operatorname{div}$ (blue curve); $i_{0} 10 \mathrm{~A} / \operatorname{div}$ (red curve), $i_{L 1}$ to $i_{L 4} 5 \mathrm{~A} /$ div; (b) boost mode, $x$-axis, $1 \mathrm{~ms} / \mathrm{div}, y$-axis, $V_{d} 100 \mathrm{~V} / \operatorname{div}$ (black curve), $i_{d} 2 \mathrm{~A} / \operatorname{div}$ (green curve), $i_{\text {ref }} 2 \mathrm{~A} / \operatorname{div}$ (blue curve) $i_{L 1}$ to $i_{L 4} 2 \mathrm{~A} /$ div. 
The simulations and experiments were performed under the same conditions as in the case of current-programmed mode control. In buck operation mode (Figure 15a), the startup of the converter and response to the changing load were evaluated. First, the converter was started and desired value of current $i_{L}$ was set from $0 \mathrm{~A}$ to $200 \mathrm{~A}$. In the transient, a small overshoot can be observed, which remained within the prescribed range. The changing load response evaluation was performed when the load changed: $R_{0}=14.6 \Omega \rightarrow 9.5 \Omega \rightarrow 14.6 \Omega$. There was only a minor resulting variation of the total inductor current $i_{L}$ in the transient. As it was expected, subharmonic oscillations were not present, since the CR was applied. Simulation analysis for boost converter operation (Figure 15b) was also performed for startup and the changing load. The inductor current $i_{L}$, which was under control, only changed for a small value in the transient (see inductor currents $i_{L 1} \ldots i_{L 4}$ ), whereas the current $i_{d}$ changed dependent on load variation, which was performed for: $R_{d}=60 \Omega \rightarrow 30 \Omega \rightarrow 60 \Omega$. Again, it can be observed that the subharmonic oscillations were not present. The experiments were also performed for startup and changing load for buck and boost operation mode. In buck mode (Figure 16a), some overshoot can be observed on the phase current at startup, whereas, when the load is changed, the phase current variations are small. Regarding Figure 16a, it shall be noted that the $i_{0}$ represents the output current, which, due to the presence of the output capacitor, differs from the total inductor current $i_{L}$. In the boost operation mode, there is no overshoot in the startup (Figure 16b). Again, the inductor currents $i_{L 1} \ldots i_{L 4}$ remain within limits when the load is changed. Like in the simulation results, the absence of the subharmonic oscillations is evident, as expected.

\subsection{Voltage Control}

In order to perform the output voltage control in the buck and boost operation, the closed loop transfer function $\widetilde{v}_{0}(s) / \widetilde{v}_{R E F}(s)$ or $\widetilde{v}_{d}(s) / \widetilde{V}_{R E F}(s)$ was derived using Table 3 and Figure 9 as follows:

$$
\left.\frac{\widetilde{v}_{x}(s)}{\widetilde{V}_{R E F}(s)}\right|_{\widetilde{v}_{g}=0}=\frac{G_{v d}(s) F_{m} C_{v}(s)}{1+F_{m}\left(G_{i d}(s) F_{h f}(s)+C_{v}(s) G_{v d}(s)+F_{v} G_{v d}(s)\right)},
$$

where the voltage controller $C_{v}$ is represented with the transfer function $\left(C_{v}(s)=K_{v} \frac{T_{v} s+1}{s T_{v}}\right.$, and $\widetilde{v}_{x}$ can be either $\widetilde{v}_{0}$ or $\widetilde{v}_{d}$, for buck or boost conversion, respectively. The parameters $K_{v}$ and $T_{v}$ represent PI voltage controller gain and time constant, respectively $\left(K_{v}=2, T_{v}=2.5 \mathrm{~ms}\right.$, for buck, and $K_{v}=1, T_{v}=5 \mathrm{~ms}$ boost operation). Figure $17 \mathrm{a}, \mathrm{b}$ show frequency response extracted from Equation (22) as $F_{m}\left(G_{i d}(s) F_{h f}(s)+C_{v}(s) G_{v d}(s)+F_{v} G_{v d}(s)\right)$ for controller parameter design. With the choice of the parameters $K_{v}$ and $T_{v}$, it is assured that the open loop transfer function magnitude is lower than $0 \mathrm{~dB}$ when the phase is $180^{\circ}$ for both buck and boost operation mode. As it was the case in the current control with the use of the PI compensator $C_{i}(s)$, the transfer function of the voltage controller $C_{v}(s)$ is included in Figure 17a,b as a reference, in order to represent the impact on the closed loop behaviour.

Closed loop frequency response for voltage control with transfer function featured in Equation (22) is presented in Figure 18a,b. The stable operation and closed loop bandwidth can be observed. Again the transfer function $C_{v}(s)$ is featured on the Bode plots as a reference.

Figure 19a,b show transient responses, obtained with simulations. The same values of parameters were also used for experimentation (Figure 20a,b). Because the parameters were again calculated for the single phase current, the output of the controller or the controller gain had to be divided by the number of phases in the simulations and experiments. 


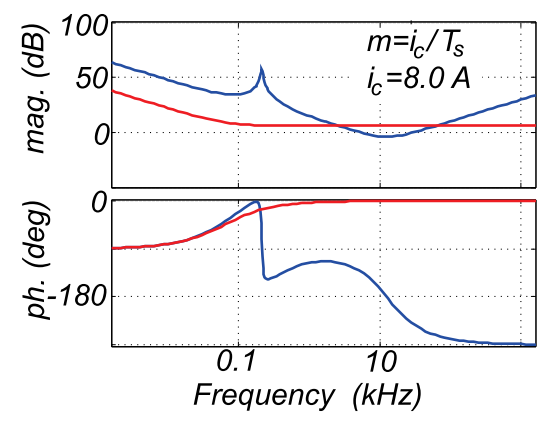

(a)

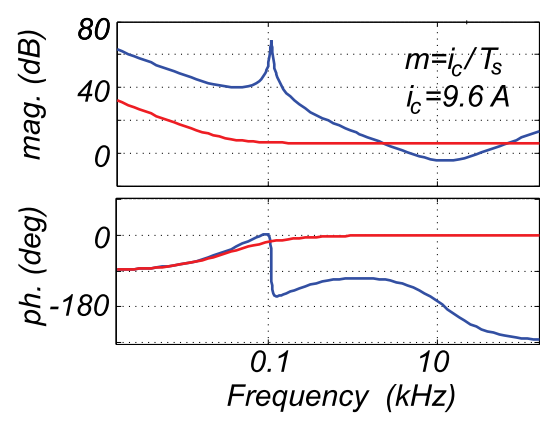

(b)

Figure 17. Frequency response, voltage control, $F_{m}\left(G_{i d}(s) F_{h f}(s)+C_{v}(s) G_{v d}(s)+F_{v} G_{v d}(s)\right.$ ) (blue curve) and $C_{v}(s)$ (red curve), for (a) buck and; (b) boost controller design.

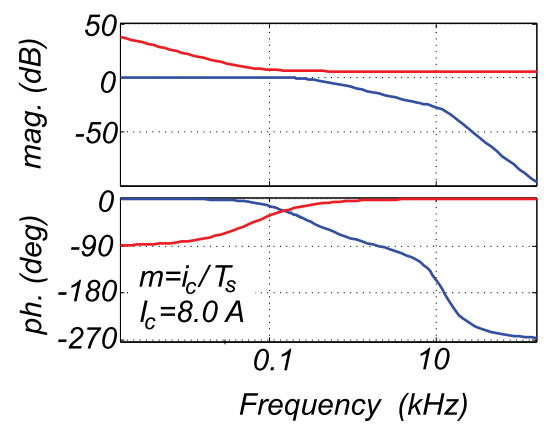

(a)

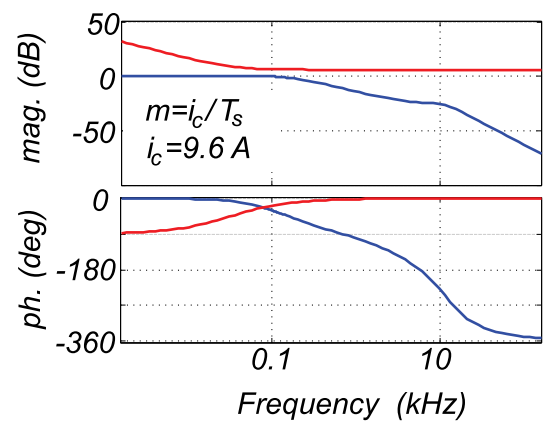

(b)

Figure 18. Frequency response, voltage control, closed loop (blue curve) and $C_{v}(s)$ (red curve), for (a) buck and; (b) boost controller design.

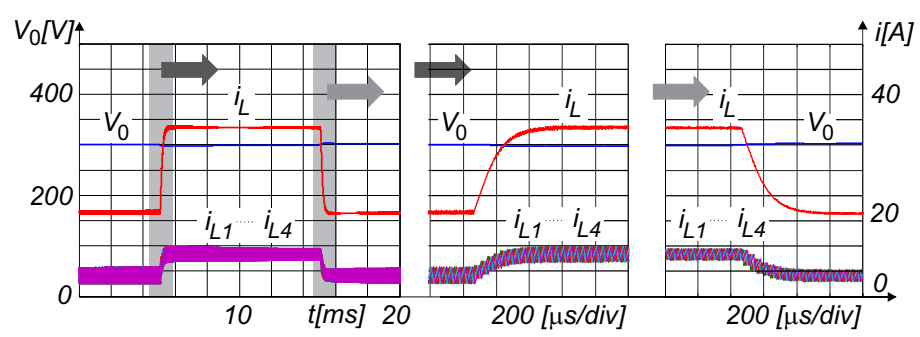

(a)

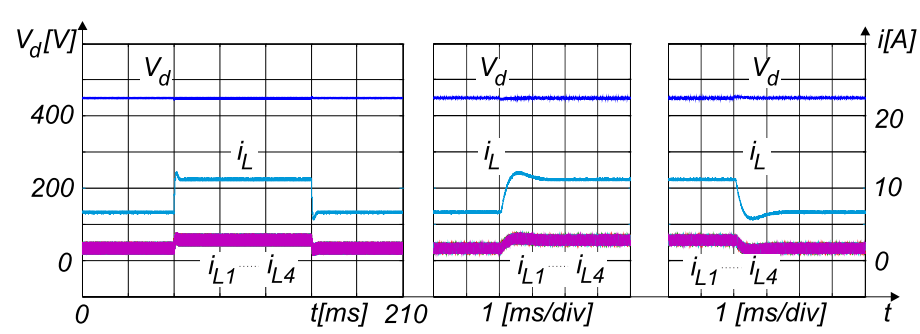

(b)

Figure 19. Simulation results, output voltage control at load transients (cut outs at load change); With current modulator, CR and PI voltage compensator; (a) buck mode ( $V_{0}$ (blue curve), $i_{L}$ (red curve), $i_{L 1}$ (green curve), $i_{L 2}$ (violet curve), $i_{L 3}$ (cyan curve), and $i_{L 4}$ (dark red curve)); (b) boost mode ( $V_{d}$ (blue curve), $i_{d}$ (light blue curve), $i_{L 1}$ (green curve), $i_{L 2}$ (violet curve), $i_{L 3}$ (cyan curve), and $i_{L 4}$ (dark red curve)). 

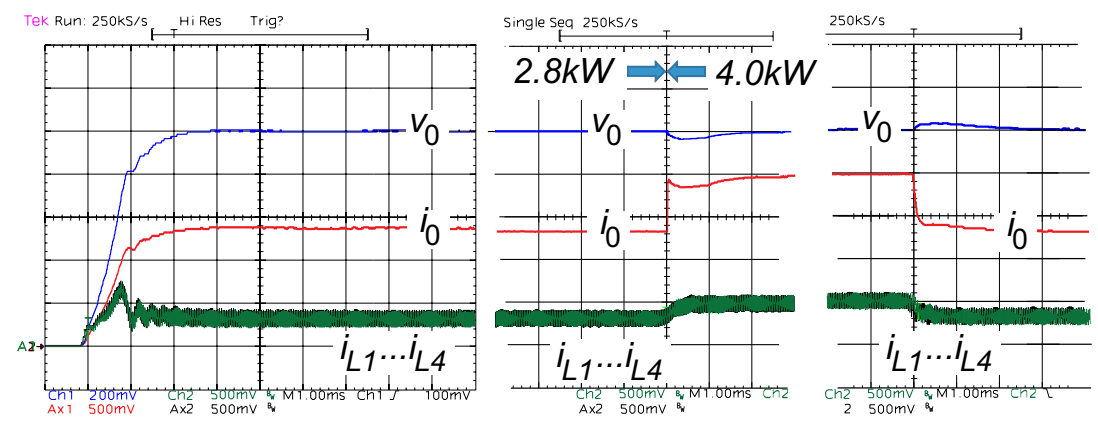

(a)
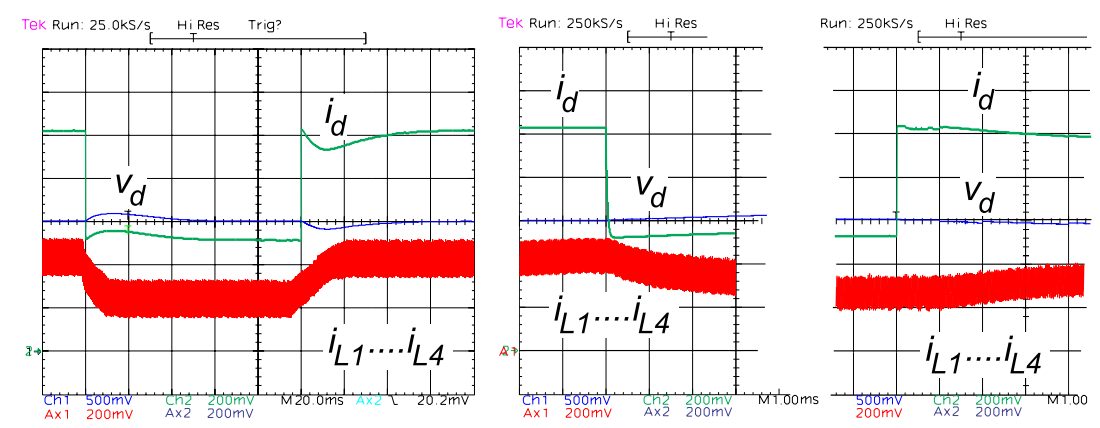

(b)

Figure 20. Experimental results, voltage control, when DR with $C R$ and PI controller are applied; (a) buck converter operation; $x$-axis $1 \mathrm{~ms} / \mathrm{div}, y$-axis, $V_{0} 40 \mathrm{~V} / \mathrm{div}$ (blue curve); $i_{0} 5 \mathrm{~A} / \mathrm{div}$ (red curve) $i_{L 1}$ to $i_{L 4} 5 \mathrm{~A} / \mathrm{div}$ (green curve); (b) boost converter operation; $x$-axis $1 \mathrm{~ms} / \mathrm{div}$, $y$-axis, $V_{d} 100 \mathrm{~V} / \operatorname{div}$ (blue curve); $i_{d} 2 \mathrm{~A} / \operatorname{div}$ (green curve), $i_{L 1}$ to $i_{L 4} 2 \mathrm{~A} / \operatorname{div}$ (red curve).

Simulation results were obtained under the same conditions as for the current-programmed mode control and current control with the use of a PI compensator. For the buck operation, the load changed: $R_{0}=14.6 \Omega \rightarrow 9.5 \Omega \rightarrow 14.6 \Omega$. Only small voltage variation can be observed for the voltage $V_{0}$ in Figure 19a. The same observation can be made for the voltage $V_{d}$ in the boost operation mode (load changed: $R_{d}=60 \Omega \rightarrow 30 \Omega \rightarrow 60 \Omega$, Figure $19 \mathrm{~b}$ ). As was the case in the current control, the absence of the subharmonic oscillations can be observed again.

Experimental results obtained under similar circumstances are presented in Figure 20a,b, where Figure 20a features operation in the buck converter mode, and Figure 20b represents the boost converter operation. The PI compensator parameters and appropriate CR slope were designed as proposed in $[33,34]$. In the buck operation mode, the converter was first started, as it is featured in Figure 20a. The transient without overshoot can be observed for the voltage $V_{0}$, whereas an overshoot is present in the inductor currents $i_{L 1} \ldots i_{L 4}$. Again, it is important to note that the output current $i_{0}$ is the load current and not the total inductor current $i_{L}$. When the load is changed $\left(R_{0}=14.6 \Omega \rightarrow 9.5 \Omega \rightarrow 14.6 \Omega\right.$, like in simulations), a small voltage transient can be observed, which is within the prescribed limits in magnitude and time. The output current $i_{0}$ value is load dependent. In the boost operation mode (Figure 20b), the results are presented for the changing load $\left(R_{d}=60 \Omega \rightarrow 30 \Omega \rightarrow 60 \Omega\right.$, again the same as in simulations). A small overshoot can be observed in the transient when the load is changed. The value of current $i_{d}$ is load dependent. Again, the subharmonic oscillations are not present. From the simulation and experimental results, it can be observed that the dynamic response of the applied control is fast. Likewise, over voltage and under voltage dynamic errors are low for all the cases, whereas the static error is not present when the PI compensator is applied for the current and voltage control. Thus, the operation of a BM DC-DC converter satisfies the requirements set by the testing setup. 


\section{Conclusions}

A bidirectional multiphase DC-DC converter to be applied in the testing setup for the testing of powertrains is proposed in this paper. With the application of such converters, the testing site enables testing of a wide variety of electric powertrains with different voltages applied to their power supply (DC-link). The bidirectional structure enables the four-quadrant operation of the drive. As such, it can also be used for the power supply of the dynamometer, providing the loading torque. Additionally, only relatively low power is required to be drawn from the power grid, since only the power losses need to be covered and, thus, the battery does not require constant charging. The multiphase interleaved converter was chosen in order to reduce the current and voltage ripple and, thereby, enable the use of smaller inductors, as well as lower current requirements for the transistors used. The BM DC-DC converter was controlled using a current-programmed mode control algorithm, based on measured integrals of the inductor current, input and output voltage, performed by using VCOs. The current dynamic reference was introduced into the proposed control, in order to achieve the stable current-programmed mode control. Additionally, a PI compensator was applied to eliminate the static error. An analytical analysis was introduced to represent the applicability of the measurement principle, dynamic reference calculation and choice of parameters. The proposed measurement principle is essential for the reaching of requirements of the high-quality testing of powertrains. It was applied in order to increase the rejection of switching disturbances appearing during the measurements because of the switching operations of the transistors in the converter and connected equipment. A small signal analysis was used for the control design, enabling the proper setting of controller bandwidth and other parameters, as well as disturbance rejection. The interaction of the BM DC-DC converter with the $\mathrm{DC}-\mathrm{AC}$ converter shall result in some problems that are not represented in this paper because the ohmic load was applied (tested by electronic load Chroma 63804). These effects will be the subject of studies in the future research work. Simulation results for the converter operating as either buck or boost, in current or voltage mode control, verified the proposed approach. Experimental results are also included, on a bidirectional multiphase $6 \mathrm{~kW}$ DC-DC converter operated in buck and boost mode. Tests were also performed for the minimal and maximal required power, thus proving the operation in the complete power range.

Author Contributions: M.R. designed and performed the necessary controls, M.M. and M.T. designed and performed the simulations and set-up the experimentation; all authors contributed analysis tools, analysed the data and wrote the paper.

Funding: This research received no external funding

Conflicts of Interest: The authors declare no conflict of interest.

\section{Abbreviations}

The following abbreviations are used in this manuscript:

Acronyms

$\begin{array}{ll}\text { BM DC-DC } & \text { Bi-Directional Multi-Phase DC-DC Converter } \\ \text { CCM } & \text { Continuous Current Mode } \\ \text { CPC } & \text { Current-Programmed Control (current programmed controller) } \\ \text { CR } & \text { Compensating Ramp } \\ \text { DR } & \text { Dynamic Reference } \\ \text { DSP } & \text { Digital Signal Processor } \\ \text { FPGA } & \text { Field-Programmable Gate Array } \\ \text { PI } & \text { PI compensator (controller) } \\ \text { PWM } & \text { Pulse Width Modulation } \\ \text { VCO } & \text { Voltage Control Oscillator }\end{array}$


Nomenclature

$A_{\text {v }}$

$A_{0}$

$A(j \omega)$

$C_{d}$

$C_{i}(s)$

$C_{v}(s)$

$\mathrm{C}_{0}$

F

$\widetilde{e}$

$F_{g}$

$F_{h f}(s)$

$F_{i r x}$

$F_{i L x}$

$F_{m}$

$F_{v}$

$F_{v d}$

$F_{v 0}$

$f_{b i}$

$f_{b v}$

$f_{c r}$

$f_{i x}$

$f_{s}$

$f_{v c o}$

$f_{u}$

$f_{0}$

$G_{i}(j \omega)$

$G_{i d}(s)$

$G_{i g}(s)$

$G_{i o}$

$G_{v}(j \omega)$

$G_{v d}(s)$

$G_{v g}(s)$

$G_{v o}$

$I_{R E F}$

$I_{\text {ref }}$

$\widetilde{I}_{R E F}$

$i_{L}$

$\widetilde{i}_{L x}$

$i_{L x}$

$i_{L 1}$

$i_{L 2}$

$i_{L 3}$

$i_{L 4}$

$i_{c}$

$i_{d}$

$i_{\text {min }}$

$i_{\text {ref }}$

$\tilde{i}_{\text {ref }}$

$i_{0}$ voltage measurement gain

open-loop gain of the amplifier at the frequency $f=\omega /(2 \pi)=0 \mathrm{~Hz}$

frequency dependent gain of the operational amplifier

input capacitance

current compensator (controller) transfer function

voltage compensator (controller) transfer function

output capacitance

VCO output

current control error in small-signal model

input voltage-to-duty cycle gain

high-frequency term

current reference $i_{\text {ref }}$ in area space

integral inductor current

modulation gain

output-voltage-to-control gain

integral input voltage

integral output voltage

bandwidth of the current measurement chain [Hz]

bandwidth of the voltage measurement chain [Hz]

critical frequency for phase margin

instantaneous VCO frequency $\left(f_{v c o}\right)$ for inductor current

Converter switching frequency $\left(1 / T_{S}\right)$

VCO frequency

instantaneous VCO frequency for voltages

free-running frequency of the $\mathrm{VCO}$ when $V_{\text {in }}=0 \mathrm{~V}$

current closed-loop frequency characteristics of measurement circuit

duty-cycle-to-current-output transfer function

voltage-input-to-current-output transfer function

closed-loop gain of the inductor current measurement circuit up to frequency $f_{b i}$

voltage closed-loop frequency characteristics of measurement circuit

duty-cycle-to-voltage-output transfer function

voltage-input-to-voltage-output transfer function

closed-loop gain of the inductor current measurement circuit up to frequency $f_{b v}$ reference value of total inductor current with compensation (PI compensator)

reference value of inductor current without compensation (PI compensator)

reference value variation for phase current (outer control loop)

total inductor current

current output in small-signal model

inductor current, phase $x$

inductor current, phase 1

inductor current, phase 2

inductor current, phase 3

inductor current, phase 4

compensating current

input load current

current at the start of VCO operation

desired value of inductor current with compensation

current reference variation in small-signal model (inner control loop)

output load current 


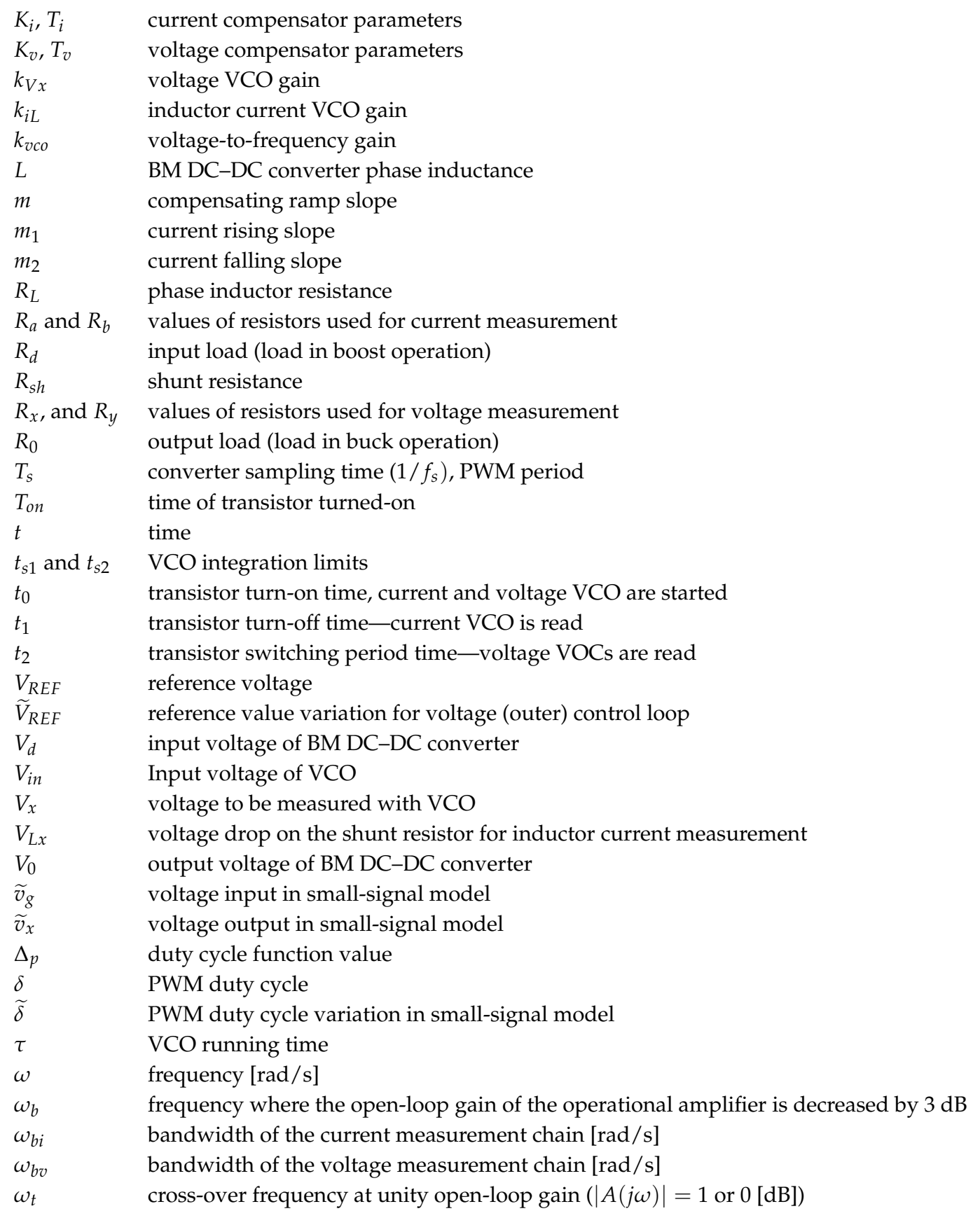

\section{References}

1. Saponara, S. An Actuator Control Unit for Safety-Critical Mechatronic Applications with Embedded Energy Storage Backup. Energies 2016, 9, 213. [CrossRef]

2. IEC/ISO. Functional Safety of Electrical/Electronic/Programmable Electronic Safety-Related Systems; IEC 61508 Parts 1-7, 2nd ed. 4/2010; IEC: Geneva, Switzerland, 2010.

3. ISO 26262:2011. Road Vehicles-Functional Safety; International Organisation for Standardisation; ISO: Geneva, Switzerland, 2011.

4. Newton, R.W.; Betz, R.E.; Penfold, H.B. Emulating Dynamic Load Characteristic Using a Dynamic Dynamometer. In Proceedings of the IEEE Power Electronics and Drive Systems (PEDS), Singapore, 21-24 February 1995; pp. 465-470.

5. Akpolat, Z.H.; Asher, G.M.; Clare, J.C. Dynamic Emulation of Mechanical Loads Using a Vector Controlled Induction Motor-Generator Set. IEEE Trans. Ind. Electr. 1999, 46, 370-379. [CrossRef] 
6. Rodič, M.; Jezernik, K.; Trlep, M. Feedforward and feedback approach for the dynamic emulation of mechanical loads. In Proceedings of the Symposium on Power Electronics, Electrical Drives, Automation and Motion, Capry, Italy, 16-18 June 2004; pp. 555-560.

7. Bose, B.K. Power Electronics and Motor Drives: Advances and Trends; Elsevier Inc.: New York, NY, USA, 2006.

8. Shabestari, P.M.; Ziaeinejad, S.; Mehrizi-Sani, A. Reachability analysis for a grid-connected voltage-sourced converter (VSC). In Proceedings of the IEEE Applied Power Electronics Conference and Exposition (APEC), San Antonio, TX, USA, 4-8 March 2018; pp. 2349-2354.

9. Trzynadlowski, A.M. Introduction to Modern Power Electronics; Wiley: New York, NY, USA, 1998.

10. Adam, G.P.; Anaya-Lara, O.; Burt, G.; Mconald, J.R. Comparison between flying capacitor and modular multilevel inverter. In Proceedings of the 35th Annual Conference of the IEEE Industrial Electronics Society, Porto, Portugal, 3-5 November 2009.

11. Miceli, R.; Schettino, G.; Viola, F. A Novel Computational Approach for Harmonic Mitigation in PV Systems with Single-Phase Five-Level CHBMI. Energies 2018, 11, 2100. [CrossRef]

12. Hoon, Y.; Mohd Radzi, M.A.; Hassan, M.K.; Mailah, N.F. Control Algorithms of Shunt Active Power Filter for Harmonics Mitigation: A Review. Energies 2017, 10, 2038. [CrossRef]

13. Zhang, C.; Guo, Q.; Li, L.; Wang, M.; Wang, T. System Efficiency Improvement for Electric Vehicles Adopting a Permanent Magnet Synchronous Motor Direct Drive System. Energies 2017, 10, 2030. [CrossRef]

14. Yu, F.; Cheng, M.; Chau, K.T.; Li, F. Control and Performance Evaluation of Multiphase FSPM Motor in Low-Speed Region for Hybrid Electric Vehicles. Energies 2015, 8, 10335-10353. [CrossRef]

15. Mousavi Sangdehi, S.M.; Hamidifar, S.; Kar, N.C. A Novel Bidirectional DC/AC Stacked Matrix Converter Design for Electrified Vehicle Applications. IEEE Trans. Veh. Technol. 2014, 63, 3038-3050. [CrossRef]

16. Zhang, Z.; Ge, X.; Tian, Z.; Zhang, X.; Tang, Q.; Feng, X. A PWM for Minimum Current Harmonic Distortion in Metro Traction PMSM With Saliency Ratio and Load Angle Constrains. IEEE Trans. Power Electr. 2018, 33, 4498-4511. [CrossRef]

17. Pillay, P.; Krishnan, R. Modeling, simulation, and analysis of permanent-magnet motor drives. I. The permanent-magnet synchronous motor drive. IEEE Trans. Ind. Appl. 1989, 25, 265-273. [CrossRef]

18. Garcia, O.; Zumel, P.; de Castro, A.; Cobos, A. Automotive DC-DC bidirectional converter made with many interleaved buck stages. IEEE Trans. Power Electr. 2016, 21, 578-586. doi:10.1109/TPEL.2006.872379. [CrossRef]

19. Xue, L.-K.; Wang, P.; Wang, Y.-F.; Bei, T.-Z.; Yan, H.-Y. A Four-Phase High Voltage Conversion Ratio Bidirectional DC-DC Converter for Battery Applications. Energies 2015, 8, 6399-6426. [CrossRef]

20. Long, B.; Jeong, T.W.; Deuk Lee, J.; Jung, Y.C.; Chong, K.T. Energy Management of a Hybrid AC-DC Micro-Grid Based on a Battery Testing System. Energies 2015, 8, 1181-1194. [CrossRef]

21. Vidal-Idiarte, E.; Martnez-Salamero, L.; Guinjoan, F.; Calvente, J.; Gomariz, S. Sliding and fuzzy control of a boost converter using an 8-bit microcontroller. IEE Proc. Electr. Power Appl. 2004, 151, 5-11. [CrossRef]

22. Simon-Muela, A.; Petibon, S.; Alonso, C.; Chaptal, J.L. Practical implementation of a high-frequency current-sense technique for VRM. IEEE Trans. Ind. Electr. 2008, 55, 3221-3230. [CrossRef]

23. Kurokawa, F.; Kajiwara, K. A New Digital Average Current-Injected Control DC-DC Converter Using VCO. In Proceedings of the International Conference on Electrical Machines and Systems (ICEMS), Beijing, China, 20-23 August 2011;

24. Qiu, Y.; Liu, H.; Chen, X. Digital Average Current-Mode Control of PWM DC-DC Converters without Current Sensors. IEEE Trans. Ind. Electr. 2010, 57, 1670-1677.

25. Liu, K.-B.; Liu, C.-Y.; Liu, Y.-H.; Chien, Y.-C.; Wang, B.-S.; Wong, Y.-S. Analysis and Controller Design of a Universal Bidirectional DC-DC Converter. Energies 2016, 9, 501. [CrossRef]

26. Nguyen, D.-D.; Nguyen, D.-H.; Funabashi, T.; Fujita, G. Sensorless Control of Dual-Active-Bridge Converter with Reduced-Order Proportional-Integral Observer. Energies 2018, 11, 931. [CrossRef]

27. Tahir, S.; Wang, J.; Baloch, M.; Kaloi, G. Digital Control Techniques Based on Voltage Source Inverters in Renewable Energy Applications: A Review. Electronics 2018, 7, 18. [CrossRef]

28. Liu, Y.; Yin, S.; Pan, X.; Wang, H.; Wang, G.; Peng, J. Effects of Nonlinearity in Input Filter on the Dynamic Behavior of an Interleaved Boost PFC Converter. Energies 2017, 10, 1530. [CrossRef]

29. Gow, J.A.; Manning, C.D. Novel fast-acting predictive current mode controller for power electronic converters. IEE Proc. Electr. Power Appl. 2001, 148, 133-139. [CrossRef] 
30. Matsuo, H.; Kurokawa, F.; Asano M. Over-current Limiting Characteristics of the DC-DC Converter with a New Digital Current-Injected Control Circuit. IEEE Trans. Power Electr. 1998, 13, 645-650. [CrossRef]

31. Kurokawa, F.; Sukita, S. A New Model Control DC-DC Converter to Improve Dynamic Characteristics. In Proceedings of the IEEE PEDS, Bangkok, Thailand, 27-30 November 2007; pp. 763-767.

32. Vorperian, V. Simplified Analaysis of PWM Converters using the Model of PWM switch Part I: Continuous Conduction Mode. Trans. Aerosp. Electr. Syst. 1990, 26, 490-596. [CrossRef]

33. Vorperian, V. Simplified Analaysis of PWM Converters using the Model of PWM switch Part II: Discontinuous Conduction Mode. Trans. Aerosp. Electr. Syst. 1990, 26, 497-505. [CrossRef]

34. Ridley, R.B. A New Small-Signal Model for Current Mode Control. Ph.D. Thesis, Virginia Polytechnic Institute and State University, Blacksburg, VA, USA, 1990.

35. Texas Instruments, LMH6611: Single Supply 345 MHz Rail-to-Rail Output Amplifiers. Texas Instruments, 2013. Available online: http:/ / www.ti.com/lit/ds/symlink/lmh6611.pdf (accessed on 31 July 2018).

36. Sedra, A.S.; Smith, K.C. Microelectronic Circuits, 6th ed.; Oxford Series in Electrical \& Computer Engineering; Oxford University Press: Oxford, UK, 2009;

37. Erickson, R.W.; Maksimovič, D. Fundamentals of Power Electronics; Kluwer Academic Publishers Group: New York, NY, USA, 2001.

38. Truntič, M.; Milanovič, M. Voltage and current-mode control for a buck-converter based on measured integral values of voltage and current implemented in FPGA. IEEE Trans. Power Electr. 2014, 29, 6686-6699. [CrossRef]

(C) 2018 by the authors. Licensee MDPI, Basel, Switzerland. This article is an open access article distributed under the terms and conditions of the Creative Commons Attribution (CC BY) license (http:/ / creativecommons.org/licenses/by/4.0/). 